\title{
Leopold von Buch's Leben und Wirken bis zum Jahre 1806.
}

Von

\section{J. E w a I d.}

I) Ruhm, der grösste Geolog seiner Zeit gewesen zu sein, ist Leopold von Buch unbestritten. So wesentlich hat er dazu beigetragen, die Geologie auf ihre jetzige Stufe zu heben, so innig ist scin Name nit allen geologischen Fragen verwebt, welche die neuere Zeit lat entstehen sehn, dass man mit Recht hat sagen können, die Geschichte seiner literarischen Wirksankeit sei zugleich die Gesehichte der Geologie in der ersten Hälfte dieses Jahrhunderts. Während er die Wissenschaft mit den Schatz von Beobachtungen und Thatsachen bereicherte, welche er in einem langen rastlosen Leben einsammelte, während or auf diese Weise in grossem Maassstabe Theil nahm an der gerïuschlosen Herbeischaffung des Materials, aus welchem sich nur allmählich ein festes Lehrgebäude aufbaut, gab er zugleich durch Aufstellung seiner berïhmten Theorien den Angelpunkt, un welchen sich alle geologische Speculation bewegte, und stempelte so dureh den mächtigen Einfluss seines schöpferischen Geistes die Zeit, welche auf die Werner'sche folgte, zur Buch'sehen Periode in der Geschichte der geologisehen Wissenschaften.

Seine Wirksankeit noch zu vermehren, kamen die Beziehungen hinzu, in denen Buch zu einem grossen Theil der mitlebenden Geologen stand. Während er mit den älteren einen fruehtbaren Austausch der Gedanken und Erfahrungen unterhielt, wirkte er auf dic juingeren.durch 
Mittheilung und Entgegennahme gleich ermunternd, und nicht selten sah man ihn wissenschaftliche Unternehmungen durch eigenes Eingreifen fördern und unterstützen. Eine Anregung wie die von ihm ausgehende zu ermöglichen, dazu mussten die Tiefe und Vielseitigkeit seines Wissens, seine Begeisterung für die Wissenschaft, sein Ansehn und seine Lebensstellung sich vereinigen. Als er neunundsiebzig Jahre alt seine Laufbahn endete, sahen sich zahlreiche therlebende Fachgenossen auch von einem persönlichen Verlust betroffen, der nicht zu ersetzen war.

Es konnte nicht fehlen, dass einem Manne von so hoher Bedeutung bald nach seinem Hintritt durch Darstellung seiner Verdienste Denkmäler gesetzt wurden. Unter ihnen haben wir vortreffliche aufzuweisen. Dennoch schien es, dass als Beigabe zu seinen gesammelten Schriften die Schilderung von dem Verlauf seines reichen Lebens, gleichsam der Faden, an dem seine Werke sich aufreihen, hinzugefügt werden mïsse. Diese Schilderung bis zu dem Punkte zu führen, bis zu welchem Buch's chronologisch geordnete Schriften dieses Bandes reichen, also bis zunı Jahre 1806, ist der Zweck der folgenden Seiten. Die Fortsetzung wird mit dem Erscheinen der ferneren Bände verbunden werden.

Wenn zur Vervollständigung der hier begonnenen Lebensskizze manche weniger bekannte Thatsachen angeführt werden können, so ist dies dem Umstande zuzuschreiben, dass die hinterbliebenen Verwandten Leopold von Buch's den schriftlichen Nachlass desselben zu diesem Zweck mit dankenswerthester Bereitwilligkeit zur Verfügung gestellt haben.

Die von Buch'sche Familie, schon im zwölften Jahrhundert als eine sehr angesehene der Altmark genannt, liess sich später in der Uekermark nieder und besass daselbst bereits im dreizehnten Jahrhundert unter anderen Ländereien ihr Stammgut Stolpe bei Angermitinde.

Leopold von Buch's Vater, der Geheime Legationsrath von Buch, vermählte sich im Jahre 1766 mit einer nach Zeugnissen der Zeitgenossen durch Charakter und Geist ausgezeichneten Dame, der Tochter des Majoratsherrn von Arnim auf Sucow und brachte die späteren Jahre seines Lebens, beschäftigt mit literarischen Arbeiten, namentlich mit Abfassung einer Geschichte der Mark Brandenburg in stiller $\mathrm{Zu}$ rückgezogenheit auf Schloss Stolpe zu. 
Hier wurde der nachmals berühmte Geolog am 26. April 1774 geboren.

Aus seinen Kinderjahren wissen wir kaum etwas Anderes, als dass er schon früh einen sorgfältigen häuslichen Unterricht erhielt. Wie die Eigenschaften, welche den grossen Gelehrten aus ihm gemacht haben, sich bereits im Knaben ankïndigten, darïber hat sich keine Nachricht erhalten. Leider sind wir eben so wenig mit den näheren Umständen bekannt, unter denen scin schon im funfzehnten Lebensjahre gefasster Entschluss, sich dem Bergbau zuzuwenden, entstanden ist. Wahrscheinlich ist es, dass die Liebe zur Naturbetrachtung frith in ihm erwachte, und dass eine Laufbahn, welche eine stete Verbindung mit den Naturwissenschaften zuliess, ihm vorzugsweise zusagte. Wenn wir ausserdem, unter Anderm aus von Dechen's vortrefflicher Rede über Leopold von Buch, erfahren, dass der damalige Minister von Heinitz es sich habe angelegen sein lassen, vielversprechende Kräfte zum Bergwesen heranzuziehen, so mag es wohl diesem letzteren Umstande mit zuzuschreiben sein, dass zwei durch äussere Lebensverhältnisse begünstigte, mit seltenen Geistesanlagen ausgestattete junge Männer wie Leopold von Buch und Alexander von Humboldt gleichzeitig dasselbe Fach ergriffen.

Nachdem der junge Buch das Jahr 1789 in Berlin zugebracht hatte, um sich durch Beschäftigung mit Mineralogie, Physik und Chemie fir seinen Beruf vorzubereiten, sehen wir ihn am 10. Juni 1790 sechzehn Jahre alt in die Bergakademie zu Freiberg eintreten, welche unter Werner's berỉhmter Leitung der Sammelplatz für Alle war, welche bergmännischen und geognostischen Studien oblagen. Seine Eltern hatten ihn der persönlichen Obhut Werner's anvertraut, in dessen Hause er längere Zeit wohnte. Dieser soll vom ersten Augenblick an die ausgezeichneten Fähigkeiten seines Pflegebefohlenen klar erkannt und ihm das Prognostikon einer bedeutenden Zukunft gestellt haben. Er beschäftigte sich viel und gern mit demselben und legte Werth darauf, sich in ihm einen Apostel seiner Lehre heranzubilden, während Buch in Werner nicht allein seinen Meister, sondern zugleich seinen väterlichen Freund verehrte. Dieses innige Verhältniss zwischen Lehrer und Schüler macht es leicht erklärlich, dass, als Buch nachmals in den Fall kam, die aus der Schule mitgebrachten Ueberzeugungen mit neuen vertauschen zu missen, das Herz dabei stets mitsprach und ihm jeden Schritt erschwerte. 
vIII

Bald nach Buch begann auch der füf Jahre ältere Alexander von Humboldt seine Studien in der Freiberger Akademie. Derselbe erinnerte sich noch bis zu seinem Ende lebhaft, wie sehr Buch sich durch originelle Weise unter seinen Mitschülern auszeichnete. Da diese nicht sämmtlich ein richtiges Verständniss für dessen Eigenthlimlichkeit hatten und Buch seinerseits in der Wahl seiner Freunde streng war, so konnte die Zahl derer, mit denen er einen intimeren Umgang pflegte, nicht gross sein. $\mathrm{Zu}$ letzteren gehörte ausser Humboldt selbst, mit welchem Buch schon hier den Grund zu ihren vielfachen gegenseitigen Beziehungen legte, der junge Freiesleben, mit dem er ebenfalls von da an eine nur durch den Tod gelöste Freundschaft unterhielt.

Schon während seines Freiberger Aufenthalts trat Buch's Neigung hervor, dem Treiben der Menschen zu entfliehen und sich auf cinsamen Gebirgspfaden der Beobachtung der Natur hinzugeben. Jede nur irgend zu erübrigende Zeit benutzte er zu Ausflügen, von denen die meisten ihn in verschiedene Theile des Erzgebirges fluhrten.

Aus diesen Unternehnungen ist seine erste gedruckte Arbeit, die tiber die Karlsbader Gegend, hervorgegangen. Ausserdem sandte er über die Ergebnisse mehrerer derselben handschriftliche Berichte an den Minister von Heinitz ein, welche in den Acten der Bergbehörden auf uns gekommen sind. Sie bestehen aus dem „Journal einer Reise nach Seiffen im Oberen Erzgebirge“, dem „Journal einer geognostischen Tour nach Waldheim", beide vom Jahre 1792, und einem „Grubenberichte von Christbescheerung Erbstolln zu Grossvoigtsberg“ vom Jahre 1793.

Dass diese wäbrend seiner Anwesenheit in Freiberg entstandenen Schriften, in denen uns neben dem Bergmann bereits der aufstrebende Geognost entgegentritt, im Sinne Werner's gehalten sind, und um so mehr, als sie sich auf eben jene Landstriche beziehen, aus denen der Meister vorzugsweise die Belege zu seiner Lehre entlehnte, versteht sich von selbst. Wie Buch in seiner Arbeit tuber Karlsbad die heissen Quellen nicht aus einer tief liegenden Wärme-Ursache, sondern aus zufälligen, nahe an der Erdoberfläche stattfindenden Vorgängen abzuleiten suchte (I, $18 \mathrm{u}$. ff.)*), so war damals seine ganze Anschauungsweise eine streng neptunistische.

*) In dieser und den ähnlichen Verweisungen bezeichnet die römische Zaàl den Band von Buch's gesammelten Schriften und die arabische Zahl die Seite desselben. 
Aber wenn diese frühen Schriften auch noch vielfach das Gepräge von Jugend-Arbeiten an sich tragen, so mussten sie dennoch jedem tiefer Blickenden die ungewöhnliche Begabung ihres Verfassers verrathen. In der That tritt in ihnen tiberall das offene Auge des geborenen Beobachters hervor, überall zeigt sich cine für ein so frühes Alter seltene Gewandtheit sich des Stoffes zu bemächtigen und ihn zur Darstellung zu bringen.

So verfehlten sie denn auch nicht, den Beifall des Ministers zu erregen, der dem jungen Buch aufmunternd mittheilte, dass er sie für werth gehalten habe zur Kenntniss des Königs gebracht zu werden.

Ausser den Reisen, auf welche sich die genannten Arbeiten grïndeten, unternahm Buch während seiner Freiberger Studienzeit noch eine Reihe anderer in das Erzgebirge, von welchen sich nur spärliche Kunde erhalten hat. So besuchte er mehrere Male und mit Vorliebe die Gegend von Annaberg, wo jene viel besprochenen, auf der Höhe des Gebirges sich erhebenden Basaltkuppen und das mit ihrem Auftreten verbundene Sand- und Geschiebe-Vorkommen ihn zu sorgfältigen Untersuchungen veranlassten. Ueber das Erzgebirge hinaus ist er in jener Periode wenig gekommen. Indess fällt in dieselbe Zeit eine Reise nach den Saal- und Unstrutgegenden und von dort nach dem Kyffhäuser; auch, wie es scheint, ein Ausflug nach der Ostsee, wo die Mtindungen der Oder und die Mittel, ihre Versandung zu verhindern, ihn lebhaft beschäftigten.

Als Buch im Herbst 1793 Freiberg verliess und zunächst die Universität Halle, sodann im Frühjahr 1795 auf kuirzere Zeit die Universität Göttingen bezog, hatte er einen doppelten Zweck vor Augen.

Einestheils war es ihm mit der Verfolgung seiner practischen Laufbahn noch Ernst und beabsichtigte er, sich auf den genannten Universitäten die flir die höheren bergmännischen Aemter geforderten Kenntnisse des Rechts und der Staatswirthschaft anzueignen.

Anderentheils wünschte er seine naturwissenschaftlichen Studien daselbst fortzusetzen. Schou seit seinem ersten Eintritt in dieselben hatte es in seiner Absicht gelegen, nicht die Geologie allein, sondern ein grösseres Gebiet zum Gegenstande seiner wissenschaftlichen Thätigkeit zu machen. Jetzt hatte dieses Gebiet in seiner Vorstellung bereits eine bestimmte Form angenommen. Eine von der Geologie ausgehende, den Zusammenhang der an der Erdoberfläehe beobachtbareu Erschei- 
nungen darstellende physische Geographic war es, auf die er nunmehr hinsteuerte, und wir werden sehen, dass er, dieses Ziel während der ersten Hälfte seines Lebens festhaltend, einer der wesentlichsten Mitbegrẗnder der heutigen Behandlungsweise der genannten Disciplin geworden ist.

So zeigt sich zwar auch darin eine Uebereinstimmung zwischen Buch und Humboldt, dass Beide, dem Geiste der damaligen Zeit entsprechend, mit vielumfassenden Bestrebungen begannen; indess werden wir sehen, wie sie später weit auseinander gingen, indem Humboldt jene Bestrebungen nicht allein festhielt, sondern noch erweiterte und im Kosmos zum Abschluss brachte, während Buch es vorzog, sich mit Rücksicht auf das Anwachsen des Stoffes in jeder einzelnen Diseiplin allmählich immer mehr auf sein Hauptgebict zuriickzuziehen, alles Uebrige zu diesem in Beziehung zu setzen und dasselbe dauernd und nach allen Seiten hin als höehste Autorität zu beherrschen.

In Halle und Göttingen nahm Buch, um eine wirksame Bearbeitung jenes weiteren Feldes anzubahnen, die Physik und Chenie, mit deren Elementen er sich schon vor seinem Abgange nach Freiberg beschäftigt hatte, eifrig wieder auf. Der Geognosie scheint er damals eine Ruhezeit, die einzige während seines Lebens, gestattet zu haben.

Zwar benutzte er, ehe er sich in Halle niederliess, einen Theil des Septembers und Octobers, um mit seinem Freunde, dem Grafen Einsiedel, eine Reise durch den Harz auszuführen. Ueberhaupt wählte er jetzt den Saalkreis, das Mansfeldische und den Harz öftere Male, so wie vorher das Erzgebirge, zum Ziel seiner Wanderungen. Auch unternahm er von Göttingen aus noch eine Untersuchung verschiedener Theile des Hessischen, Thtiringischen, Coburgischen und des Fichtelgebirges, ehe er sich im Herbst 1795 nach Berlin zurïck begab.

Indess ist aus jenen Jahren von geognostischen Publicationen nichts Anderes von ihm vorhanden als einige kurze briefliche Mittheilungen ( $I, 36)$, und von umfangreicheren Schriften veröffentlichte er nur seine unter dem 9. März 1794 von Halle aus an die Linnéische Societät in Leipzig eingesandte physikalisch - chemische Abhandlung uber den Kreuzstein. Sie ist die einzige rein oryktognostischen Inhalts, die wir von ihm besitzen, und interessant als Beleg daftir, mit welcher Energic er Alles ergriff, was auf seinem wissenschaftlichen Wege lag. Inden er die Krystallform des Kreuzsteins untersuchte, rang er nach einer Schärfe der Behandlung, welche der 
damalige Standpunkt der Krystallographie noch nicht zu erreichen gestattete. Mit unendlicher Mühe suchte er, indem or die Längen der Krystallkanten mass, die krystallographischen Elemente des Minerals, die heut zu Tage vermittelst vervollkommneter goniometrischer Vorrichtungen leicht und sicher ermittelt werden, zu bestimmen. In Haüy'scher Weise erklärte er endlich eine Reihe von Phänomenen durch Aufbau der Krystalle aus Theilchen von bestinnter Form. Diese Anstrengungen machen die Theilnahme erklärlich, mit welcher er von der Zeit an die Arbeiten des genannten französischen Mineralogen verfolgte.

Nach seinem Abgange von Göttingen betrachtete Buch seine Studienzeit für beendet. Um sich jetzt, wie er sich in einem Schreiben an den Minister ausdrückte, seinem Vaterlando nützlich zu machen, bewarb er sich um eine Anstellung und erhielt bald (im Frïhjahr 1796) eine solche als Referendar bei dem schlesischen Oberbergamt, welches mit Rücksicht auf die in seinen bisherigen Arbeiten gezeigten Neigungen und Anlagen angewiesen wurde, ihn vorzugsweise mit der geognostischen Durchforschung der Provinz zu beschäftigen.

So gelangte er zu einer ihm in jeder Rtieksicht zusagenden 'Thätigkeit, bei welcher er seinen wissenschaftlichen Bestrebungen ungestört nachgehen durfte, und seine amtliche Stellung ihm nur zu Statten kam, ohne ihm irgend welche lästige Verwaltungsarbeiten aufzulegen.

Die Untersuchungen, welche Buch in Folge dieser Anstellung während der Jahre 1796 und 97 in Schlesien ausführte, hatten eine Reihe von Publicationen zur Folge.

Schon im Jahre 97 gab er als selbstständige Schrift seinen „Versuch einer mineralogischen Beschreibung von Landeck" heraus, welcher als eine durch Inhalt und Form ansprechende, zwar einem nur kleinen District gewidmete, aber durch allgemeine Betrachtungen gehobene Schilderung ungetheilten Beifall erregte und in dem deutschen Original wie in der französischen und englischen Uebersetzung weite Verbreitung fand.

Dieser folgten bald drei in den bescheidenen Schlesischen Provinzialblättern mit bürgerlichen Anzeigen zusammengedruckte Aufsätze von 1797 und 98:

Der erste derselben „über den Buchberg bei Landshut" handelt 
von der diesen Berg zusammensetzenden Melaphyrmasse, welche Buch zwar hier noch als Basalt beschreibt, aber schon in seiner Karte von Schlesien, gleichzeitig mit anderen im Text zum Basalt gestellten Gesteinen, richtig davon trennt, um sie den Porphyren anzureihen.

Der zweite Aufsatz „über den Zobtenberg“" ist dadurch bemerkenswerth, dass Buch darin zum ersten Mal die Aufmerksamkeit auf das den Gipfel dieses Berges zusammensetzende Gestein lenkte, welches er hier mit dem Namen Zobtenfels belegte, bald darauf in seinem Entwurf einer geognostischen Beschreibung von Schlesien zwar als einen mit seiner jüngeren Serpentinformation verbundenen Grünstein bezeichnete, später aber wiederum als eine selbstständige Gebirgsart festhielt und unter dem Namen Gabbro bis an die nördlichen und sidllichen Grenzen von Europa verfolgte.

Der dritte Aufsatz "über das Riesengebirge" enthält eine treffliche Schilderung des Zusammenhangs zwischen dem orographischen und geognostischen Bau dieses Gebirges.

Ebeufalls noch im Jahre 1798 veröffentlichte Buch in Moll's Jahrbüchern eine Abhandlung "tiber das Uebergangsgebirge mit einer besonderen Anwendung auf Schlesien", eine Schrift, in welcher eine für jene Zeit ausgezeichnete Darstellung von der Zusammensetzung und weiten Verbreitung dieser erst wenige Jahre vorher von Werner in dic Wissenschaft eingeführten Formation gegeben wird.

Endlich fasste Buch in dem „Entwurf einer geognostischen Beschreibung von Schlesien", den er im ersten Bande seiner Beobachtungen auf Reisen im Jahre 1802 erscheinen liess, die wichtigen Ergebnisse, die er in dieser Provinz erlangt hatte, zu einer die einzelnen Formationen mit musterhafter Klarheit und Uebersichtlichkeit behandelnden Arbeit zusammen.

An diesen Schriften tiber Schlesien besitzen wir eine höchst anzichende Anwendung der Werner'schen Erdbildungstheorien auf cinen grossen und wichtigen Landstrich dureh einen der geistvollsten Geognosten der Freiberger Schule.

Die Werner'sche Ansicht, dass alle Gesteine, die nicht aus evidenten Krateren geflossene Laven sinc, Absätze aus den Wasser seien, wird in ihrem ganzen Umfange angenonmen. Die neptunische Eutstehung des Basalts wird sogar mit besonderer Wärme vertheidigt (I, 68), indess fast möchte man glauben, weil Buch selbst schon fühlte, 
dass sie einer solchen Vertheidigung vorzugsweise bedürfe. In der That giebt er bereits bei Besprechung des Basaltrorkommens an den Schneegruben im Riesengebirge zu, dasselbe lasse sich genügend nicht neptunistisch, freilich auch nicht vulkanistisch erklären (I, 225).

Dem Werner'schen System gemäss erscheint in Buch's Arbeiten tiber Schlesien Granit als ältestes Gestein. Aus ihm bildeten sich nach jenem System der feste Kern der Erde und die ersten Hervorragungen auf der Oberfläche derselben. An diese Hervorragungen legten sich die tibrigen Gebirgsarten, der Reihe nach und wit dem Gneus beginnend, so an, dass jede schon bei ihrer Entstehung die Stelle einnahm, an der wir sie heute beobachten. Nachträgliche Aenderungen in der gegenseitigen Lage der Gesteine konnten zwar, wie angenommen wird, als Ereignisse localer Art stattfinden, nicht aber bei dem Aufbau der Gebirge in Grossen mitwirken. Da auch die Mögliehkeit continentaler Hebungen des Bodens durch die vorausgesetzte Starrheit des Erd-Innern ausgesehlossen ist, so bleibt zur Erklärung des Vorkommens von Gesteipen in grosser Höhe nichts Anderes ubrig als die Annahme gewaltiger Schwankungen des Meeresniveaus. - Mit bewundernswïrdigem Scharfsinn suchte Buch seine Beobachtungen mit diesen Theorien in Einklang zu bringen und die Verbreitung und Zusammensetzung der schlesischen Gesteine zu deuten, indem er den Fluthen, aus welchen sich jene Gesteine niedergeschlagen haben, bestimmte Strömungs-Richtungen zuschrieb. Unter Anderm führte er dies in sehr eingehender Weise an dem Conglomerate des schlesischen Steinkohlengebirges und Rothliegenden durch (I, 200-208). Bei Untersuchung der jenes Conglomerat zusammensetzenden Geschiebe hatte er nicht allein erkannt, dass dieselben lediglich von Felsarten gebildet werden, welche im schlesischen Gebirge anstehend vorkommen, sondern auch, dass sie, je näher ihrem Ursprungsorte, um so grösser, je ferner, um so kleiner sind. Die Folgerungen, welche sich hieraus auf den Weg, den sie zurïckgelegt haben mussten, ziehen liessen, ergaben, dass ihre Zerstreuung durch eine aus Sitd-West nach Nord-Ost sich bewegende Fluth vor sich gegangen sei. Mit der Voraussetzung, dass eine solche Fluth das alte krystallinische Gebirge Schlesiens in seiner jetzigen Höhe vorfand, Gesteinsmassen von ihm losriss und in Form von Geschieben in nordöstlicher Richtung fortführte, bìs dieselben sich an vorliegenden Dämmen absetzten oder durch ihre Schwere niedersanken, fand er denn 
auch die Art, wie das Conglomerat sich vor und zwischen dem altem Gebirge angehäuft hat, hinter demselben aber vermisst wird, vollständig thereinstimmend. - Durch die Annahme von Fluthen, welche zu anderen Zeiten andere Richtungen verfolgt hätten, suchte er dire Lagerung der Sandsteine im Glatzischen, des Flötzgebirges uberhaupit in verschiedenen Theilen Schlesiens, ja selbst des Gneuses und Glimmerschiefers am Riesengebirge zu erklären.

Der Werner'sche Grundsatz, dass alle Gebirgsarten ibrem Alter nach geordnet eine Progression aus dem vollkommen krystallinischem Zustande der ältesten in die mechanische Zusammensetzung der jüngeren bilden, ein Grundsatz, der auf die Altersbestimmung der Gesteine zurïckwirken musste und beispielsweise die Zurechnung sänmtlicher Porphyre zum Urgebirge nach sich zog, wurde von Buch in seinen Arbeiten ïber Schlesien ebenfalls anerkannt; innerhalb der krystallinischen Gesteine wurde zugleich eine auf ihre chemische $\mathrm{Zu}$ sammensetzung sich gritndende Reihenfolge aus älteren kieselreicheren in juingere thonreichere Gesteine, zu denen sich erst später die vorherrschend kalkigen und magnesiareichen geselit hätten, angenommen. Diese Ideen fanden in der Abhandlung uber das Uebergangsgebirge (I, 92-95), in dem Entwurf einer Beschreibung von Schlesien (an mehreren Stellen), endlich in den später zu erwähnenden Considérations sur le granit (I, 104-105) eine höchst interessante Anwendung.

Während freilich ein so strenges Festhalten an den Ideen Werner's nicht verfehlen konnte, auf die Entwicklung von Buch's eigenen Ansichten uber den Gebirgsbau Schlesiens beengend und hemmend einzuwirken, hatte er gleichzeitig mit einer anderen, von jenen Ideen unabhängigen Schwierigkeit zu kämpfen, nämlich mit der noch mangelhaften Kenntniss der geschichteten Formationen. Viele Formationsunterscheidungen, welche jetzt zu den wesentlichsten und durchgreifendsten gerechnet werden, waren noch nicht eingeführt, die eingeftihrten konnten nicht überall durehgefubrt werden. Unter dem Titel des Flötzkalkes wurden in Schlesien Gesteine vom Perm'schen System aufwärts bis zur Kreide vereinigt, und den Sandstein trennte man zwar schon in einen älteren und neueren; aber weder war es, wie die Einreihung der Kieslingswalder Gesteine in den älteren zeigt, möglich, jedem von beiden seine Grenzen genau anzuweisen, noch auch vermochte man in dem jungeren ein so neues Flötzgebirge wie die Kreide zu erkennen. Zur Beseitigung solcher 
Uebelstände versagte die Paläontologie noch ihre Mitẉirkung. Auf welchem Standpunkt diese Disciplin sich befand, beweist die Anfuhrung von Belemniten und Gartensehnecken im Kohlenkalk, der wir in der Beschreibung von Landeck begegnen. Während die Werner'sche Schule das Studium der Versteinerungen, welches heute als eines der wichtigsten Hülfsmittel für die unmittelbare Altersbestimmung der geschichteten und mittelbare der ungeschichteten Formationen gilt, vōllig hintansetzte, hat zwar Buch mit richtigem Gefühl schon bei seinen ersten Untersuchungen die Aufmerksamkeit auf die organischen Reste gerichtet; aber aus denselben wirksame Schlïsse auf die Entstehungszeit der Gesteine zu ziehen, war damals noch unmüglich.

Je lebhafter man sich die Bedeutung aller geschilderten Erschwerungen und Hemmnisse vergegenwärtigt, desto höher wird man die Leistung anschlagen, welche Buch's Arbeiten über Schlesien dennoch darbieten.

Dieselben bezeichnen nicht allein einen wesentlichen Fortsehritt in der Kenutniss dieser Provinz, sie haben nicht allein den weiteren geognostischen Untersuchungen in derselben sowie dem daselbst aufbliihenden Bergibau eine wichtige Grundlage geliefert; sondern sie waren, indem sic ein Muster tiefeindringender Forschung aufstellten, fur die Wissenschaft tiberhaupt und ihre Behandlung von durehgreifendem Einfluss.

Es würde unmöglich sein', die neuen und interessanten Einzelnheiten aufzufuhhren, welche aus diesen Arbeiten hervorgehoben zu werden verdienen, da sich deren auf jeder Seite vorfinden. Die petrographischen Beschreibungen der verschiedenen Formationen, die Mittheilungen uber die darin enthaltenen Erzlagerstätten und fremdartigen Einlagerungen der mannichfaltigsten Art, die Angaben tuber die örtliche Verbreitung der Gesteine enthalten eine Fülle davon.

Buch legte von jeher grossen Werth auf geologische Karten, welche er jeder Beschreibung grösserer Landstriche hinzugefügt wissen wollte. So. mochte er auch seine Arbeiten über Schlesien nicht ohne eine solche Beigabe in die Welt senden. Als erste mit geognostischem Colorit versehene Darstellung dieser Provinz und zu einer Zeit entstanden, wo derartige Publicationen iberhaupt zu den Seltenheiten gehörten, darf sie zu Buch's verdienstlichsten Schöpfungen seiner ersten Periode gezïhlt werden. Das Bild des Gebirgsbaues Schlesiens, wie es sich bei dem damaligen Zustande der Wissenschaft 
durch Buch's Untersuchungen gestaltet hatte, tritt daraus in seinen allgemeinen Zügen klar vor Augen.

Gegen Ende des Sommers 1797 brachte Buch seine Untersuchungen in Schlesien zu einem vorläufigen Abschluss. Er stand jetzt an einem wichtigen Wendepunkt in seinem Leben. Die Erfolge jemer Untersuchungen hatten den Entschluss in ilm zur Reife gebracht, siich fortan der Wissenschaft allein zu widmen. Aus seiner practischen Beschäftigung jene Gewandtheit in der Benutzung bergmännischer Ergebnisse mitnehmend, welche dem, der selbst einmal die Gruben befahren hat, auch bei theoretischen Untersuchungen zu Statten kommt, verliess er die Beamtenlaufbahn. Seinen Austritt erklärte er zwwar nicht förmlich, so dass er sich noch als Greis scherzweise den älltesten preussischen Bergreferendar nennen konnte; aber sein bisheriges amtliches Verhältniss löste sich von selbst durch eine grössere, ïhn auf mehrere Jahre vom Vaterlande entfernt haltende Reise. Und sehen wir ihn auch in den ersten Jahren nach seiner Rückkunft noch mehrere Male im Auftrage der obersten Bergbchörde thätig, so waren dies doch nur vereinzelte und vorübergehende Beschäftigungen.

Im August verliess er Schlesien und ging zum ersten Male uber die Grenzen seines bisherigen, auf Nord- und Mittel-Deutschland beschränkten Beobachtungsgebiets hinaus. Es galt ihm, sich in UnterItalien mit den Erscheinungen thätiger Vulkane aus eigener Anschauung bekannt zu machen und auf diese Weise die Grundlagen fur eine selbstständige Entscheidung über die in der Geologie herrschenden allgemeinen Streitfragen zu gewinnen.

Er begab sich zunächst nach Wien, um von dort über Linz, Salzburg, Innsbruck und den Brenner Italien zu erreichen. Den damaligen kriegerischen Ereignissen in Ober-Italien, wo österreichische und französische Heere einander gegentiberstanden, ist es obne Zweifel zuzuschreiben, dass er nicht schon vor Eintritt des Spätherbstes die Alpen tiberschritt. Als er in Linz anlangte, schrieb man bereits den 3. November; dennoch beschloss er, seinen Weg von hier nach Salzburg durch die Alpen des Salzkanmerguts und Salzburgischen zu nehmen, um den Bau derselben, so gut es die vorgertickte Jahreszeit noch erlauben würde, kennen zu lernen. Nachdem er sich in dieser Absicht tiber Gmtinden und Ebensce nach Ischl begeben hatte, war. 
es am letzteren Ort, wo er an! 8. November mit Alexander von Humboldt zusammentraf.

Dieser und sein Bruder Wilhelm waren nämlich auch ihrerseits mit dem Vorhaben, eine gemeinschaftliche Reise nach Italien auszufuhren, nach Wien gegangen. Dort ebenfalls durch die italienischen Wirren von der Weiterreise abgehalten, hatten sie ihren Plan aufgegeben und beschlossen, sich statt dessen nach Paris zu wenden, wo sie einen längeren Aufenthalt zu nehmen gedachten. Obgleich bald darauf zwischen den kriegführenden Mächten in Italien der Friede von Campo Formio zu Stande gekommen war, hatten sie dennoch an ihrem letzten Entschluss festgehalten und jetzt ihren Weg längs des Nordabhanges der Alpen eingescblagen, um an die Grenze Frankreichs zu gelangen.

Nach ihrer Ankunft in Salzburg mochte Alexander von Humboldt Kunde davon erhalten haben, dass Buch daselbst erwartet wurde, vielleicht war er auch schon von dessen Reiseplänen durch ilın selbst unterrichtet worden; wie dem auch sei, er trennte sich von seinem Bruder, der seine Reise vach der französischen Hauptstadt fortsetzte, und eilte seinem Landsmann und Fachgenossen nach Ischl entgegen.

Vereinigt besuchten sie jetzt Hallstadt, Aussee, die Gosau und Hallein. Am 16. November trafen sie in Salzburg ein. In Humboldt war inzwischen, wie es scheint, der Wunsch entstanden, ehe er seinem Bruder nach Paris folgte, während einiger Monate an einem ruhigen Orte ungestört zu arbeiten, und da Buch seinerseits vorziehen mochte, seinen Uebergang uber die Alpen bis zu besserer Jahreszeit aufzuschieben, so entschlossen sich Beide, in Salzburg unter wissenschaftlichen Beschäftigungen den Winter gemeinsan zu verleben, wo sie an dem Baron von Moll, dem bekannten Herausgeber der Jahrbücher für Berg- und Hüttenkunde, einen wichtigen Anhalt für ihre Bestrebungen fanden, und Buch, an der Sichwelle von Italien, die weitere Entwickelung der politischen \%ustände in jenem Lande leicht im Auge behalten konnte.

Obgleich eine fernere Durchforschung der Alpen für jetzt als völlig unthunlich hätte erscheinen können, gingen die beiden Freunde in ihrem Eifer so weit, dass sie während der letzten Tage des Novembers und eines Theils des Decembers eine zweite geologische Reise, auf welcher die Centralkette jenseit Gastein erreicht wurde, ausfihrten, und ungeachtet der Schwicrigkeiten, welche das Hochgebirge un diese 
XviII

Zeit dem Reisenden, geschweige dem Beobachter entgegenstellt, gltickte ihnen ihr Unternehmen, wie die daruber von Buch veröffentlichten Mittheilungen beweisen.

Während sie aber den grössten Theil des Winters an die Stadt gefesselt waren und Humboldt diese Zeit dàzu benutzte, die meteorologischen und eudiometrischen Untersuchungen anzustellen, durch welche sein Aufenthalt in Salzburg bezeichnet ist, beschäftigte sich Buch hauptsächlich mit schriftstellerischen Arbeiten. Hier verfasste er seine bereits erwähnte Abhandlung über das Uebergangsgebirge, welche er Moll zur Aufnahme in seine Jahrbücher ubergab. Hier schrieb er schon die Ergebnisse der beiden so eben ausgefübrten Alpenreisen nieder. Die Humboldt'schen Untersuchungen verfolgte er zwar gleichzeitig mit Theilnahme; wenn aber hier und da die Meinung geäussert worden ist, dass Buch's spätere Beschäftigungen in derselben Richtung durch das Zusammensein mit Humboldt in Salzburg hervorgerufen worden seien, so haben wir in Gegentheil gesehen, dass er von Anfang seiner Laufbahn an die Physik planmässig in den Kreis seiner wissenschaftlichen Forschung eingeschlossen hatte.

Zwar war es auch Humboldt gewesen', der auf der salzburger Reise die Beobachtung des Barometers itbernommen hatte, aber nur, damit Buch seine ganze Aufinerksamkeit den geologischen Erscheinungen zuwenden konnte. Gerade mit der Benutzung der meteorologischen Instrumente zu Höhenbestimmungen hatte er sich längst auf das Eingehendste beschäftigt, weil er von jeher in diesen Bestimmungen eine der wesentlichsten Grundlagen ftir alle Untersuchungen der Erdphysik erkannt und derselben für seine speciell geologischen Arbeiten um so mehr bedurft hatte, als nach der damals herrschenden Anschauungsweise aus der Höhe, die man die Gesteine einnehmen sah, die durchgreifendsten Schlüsse auf die Entstehungsart der Gebirge abgeleitet wurden. Die von Humboldt auf der Reise angestellten Beobachtungen sogleich für die Darstellung des Salzburgischen und Salzkammerguts verwerthen zu können, erschien ihm denn auch so wichtig, dass er trotz der durch seine begonnenen Arbeiten und seine Vorbereitungen zur Weiterreise knapp zugemessenen Zeit schon dort an die Berechnung derselben ging.

Kaum war das Frthijahr 1798 angebrochen, als Buch sich, um 
das ersehnte Italien $z u$ erreichen, von seinem Freunde trennte und allein seine Reise uber Innsbruck und den Brenner fortsetzte.

Um auch hier wie im Salzburgischen den Zusammenhang zwischen der Oberflächengestaltung und dem geognostischen Bau des Gebirges zu ermitteln, war er jetzt genöthigt, Barometer und Hammer neben einander zu benutzen.

Nachdem er sich von der geringen Passhöhe des Brenners durch Messung tiberzeugt und die Ausbildung der krystallinischen Formationen im Centrum der Alpen sorgfältig beobachtet hatte, nachdem er, angeregt durch die grossartige Entwickelung der das Eisack- und Etschthal begrenzenden Porphyrmassen nach 'Trient gelangt war, wurde er zwischen dieser Stadt und dem nahe gelegenen Pergine durch das Wiedererscheinen des Glimmerschiefers in weiter Eutferuung von der Centralkette sowie durch die Verbindung, in welcher er den Porphyr mit dem Flötzgebirge fand, in Frstaunen gesetzt und von der Mannichfaltigkeit der Erscheinungen, welche jede einzelne Formation ihm daselbst darbot, so sehr erfïllt, dass er für diese Gegend „einen der vorziliglichsten Plätze in der Gebirgslehre" in Anspruch nahm (I, 339).

Nach einem kurzen Aufenthalt in den Umgebungen von Trient verfolgte er seinen Weg, auf dem er vom Bremner bis zur oberitalienischen Ebene den Schauplatz einer seiner berühmtesten Lntersuchungen späterer Zeit streifte, durch Val Sugana nach Venedig, das er im Mai 1798 erreichte.

Aus seinem Aufenthalt in Salzburg und seinem Lebergange uber die Alpen sind folgende Schriften hervorgegangen:

Als Ergebuisse seiner winterlichen Wanderungen mit Humboldt die "geognostische Uebersicht des ïsterreichischen Salzkammerguts" und die "Reise durch Berchtolsgaden und salzburg";

sodann als Früchte seiner Beobachtungen auf dem Wege von Salzburg nach Venedig die ,barometrische Reise über den Brenner“, die sich daran anknüpfende "Vergleichung: von Bremner und MontCénis“, endlich die „Briefe aus Pergine“.

Alle diese Schriften sind in dem ersten Bande der "Beobachtungen auf Reisen", welcher im Jahre 1802 ausgegeben wurde, beisammen abgedruckt. Sie bilden ihrem Inlaalt nach ein Gauzes, wenngleich sie nicht sämmtlich in genau gleicher Zeit verfasst sind. So wurde die barometrische Reise uber den Brenner schon 1798 geschrieben und 
bald darauf, im Jahre 1799, in den Moll'schen Jahrbüchern veröffent licht, von wo sie erst, und zwar mit einigen Fortlassungen, in die Beobachtungen auf Reisen uberging; so sind die Briefe aus Pergine, welche zum ersten Male in den Schriften naturforschender Freunde zu Berlin vom Jahre 1801 gedruckt wurden, ebenfalls schon im Jahre 1798 entstanden; wogegen die Parallele zwiseben Brenner und MontCénis, wie man aus den offenbar auf eigene Anschauung gegründeten Aeusserungen über Genf und den Jura abnehmen kann, erst während Buch's Aufenthalts in Neuchâtel und zwar 1802 kurz vor ihrem Erscheinen vollendet sein kann.

In den fünf genannten Arbeiten tiber die Alpen hatte Buch in höheren Maasse noch als in jenen tiber Schlesien mit den Hemmnissen zu kämpfen, welche der damalige Zustand der Wissenschaft in den Weg legte. Die Anwendung der Werner'schen Theorien wurde hier in demselben Grade misslicher, als die zu erklärenden Phänomene an Grösse zunahmen. Auch von Gesteinen, die sich so bedeutend erheben, wie die der Alpen, musste angenommen werden, dass sie sich in ihrer jetzigen Höhe aus dem Wasser abgesetzt hätten; die Beobachtungen mussten so gedeutet werden, dass sie sich auch mit dieser Vorstellung. noch vertriigen.

Dabei wurde hier zu einer richtigen Auffassung der Gebirgsstruetur die Keuntniss der geschichteten Formationen um so unzureichender, als die alpine Ausbildungsweise dieser Formationen in Anschlag gebracht werden musste, deren Studium noch ganz in der Kindheit war. Man hatte keine Vorstellung davon, dass jüngere Gesteine, Gesteine, deren Entstehung wir heute in die Jura-, Kreide- und Tertiärperiode versetzen, einen wesentlichen Antheil an dem Aufbau der dazu für viel zu alt gehaltenen Alpen genonmen hätten. Man glaubte, in diesen Gebirge wären von geschichteten Formationen nur solehe zu suchen, welche die neuere Geognosie als paläozoische bezeichnet. So wurden alle Kalke nach unsicheren petrographischen Merkmalen zwischen dem Ucbergangsgebirge und dem Alpenkalk getheilt, welcher letztere als ein zu enormer Mächtigkeit angewachsenes Aequivalent des thiiringischen Zechsteins betrachtet wurde.

Gleichzeitig musste die Behandlung der krystallinisehen Gesteine, je mannichfaltiger dieselben in den Alpen vertreten sind, um so mehr 
durch die noch immer herrschende Werner'sche Progressionslehre beengt werden.

Aber Buch verlieh nicht allein den genannten Abhandlungen durch den Scharfsinn, womit er auch die vom Hochgebirge dargebotenen Erscheinungen nach den damals geltenden Grundansichten deutete, ein hohes Interesse, sondern förderte zugleich die Alpengeologic wesentlich durch die zahlreichen neuen Thatsachen und Ideen, welche er ihr zuführte.

Die Oberflächengestaltung der alpinen Gebirgswelt hat Buch in diesen Abhandlungen unibbertrefflich geschildert. Indem er die für das Relief der Alpen charakteristische Zerrissenheit der Berge und Steilheit der Abhänge, welche später von ihm mit einer grossen und allgemeinen die Erhebung und Aufrichtung des ganzen Gebirges hervorbringenden Gewalt in Verbindung gebracht wurde, damals noch von Ursachen rein localer Natur ableitete, machte er einen scharfsinnigen Gebrauch von der einschneidenden, abnagenden und fortschaffenden Kraft der Wasserläufe, denen er die Entstehung der Längs- und Querthäler zuschrieb, und deren Wirksamkeit er erst später jenen Erhebungs- und Aufrichtungstheorien zu Liebe auf ein Minimum herabsetzte. Wo er die Kraft der Gewässer zur Erklärung der Erscheinungen nicht für ausreichend hielt, nahm er andere, jedoch ebenfalls rein örtliche Vorgänge zu Hülfe; so erklärte er die Entstehung derjenigen Seen, welche sich wie der Hallstädter und Königssee durch ihre steilen Ränder von den übrigen unterscheiden, durch locale Einstürze im Kalkgebirge und betrachtete sie als die Reste von Wasseransammlungen, deren Abfliisse durch Einschneidung sich selbst vertieften und gleichzeitig das Niveau der Seen erniedrigten (I, 235 und 277). Die gewaltsamen Knickungen der Schichten, welche er in den Alpen vielfach beobachtete, sah er als Folgen ähnlicher localer Veränderungen in der gegenseitigen Lage der Massen, als Folgen localer Verrückungen des Schwerpunkts derselben an (I, 237).

Ueber die in den Alpen entwickelten Felsarten bringen die fünf Abhandlungen eine grosse Reihe neuer Beobachtungen. Unter den geschichteten Gesteinen war es der Alpenkalk mit seinem reichen Salzsehatz, welchem Buch eine besondere Sorgfalt widmete. Ja er fühlte schon das Bedürfniss diese mächtige Schichtenfolge zu gliedern, und wagte den Versuch die Glicderung auszuführen, indem er in der nördlichen Zone des Alpenkalks nach Färbung und Korn des Gesteins drei 
Abtheilungen unterschied (I, 239) und in der südlichen ebenfalls mehrere geognostische Niveaux auszeichnete, welche er sogar schon an ihren organischen Einschlüssen wiedererkannte (I, 329). Aber die Auffindung derjenigen Abschnitte in der Aufeinanderfolge der Alpenkalkbänke, welche den Hauptepochen in der Bildungsgeschichte der Erde entsprechen, konnte erst nachmals, als die Kenntniss der Formationen ausserhalb der Alpen weiter vorgeschritten war, durch die vereinten Anstrengungen der Geognosten, an denen Buch selbst einen so dauernden und wesientlichen Antheil nahm, gelingen.

Unter den krystallinischen Gesteinen, die er in den genannten Abhandlungen besprochen hat, ist besonders der Porphyr wegen der anziehenden Betrachtungen, welche er daran knüpte, hervorzuheben. Wie bereits oben erwähnt wurde, hatte er bei Trient diese von ihm bisher zum Urgebirge gerechnete Felsart mit Kalksteinen in enger Verbindung gesehen, deren Flötzgebirgscharakter ihm unzweifelhaft sein musste. Zum ersten Male scheinen dureh diese Beobachtung ernste Bedenken in ihm erwacht zu sein, die Natur möchte sich nicht überall dem Werner'schen Schema fügen; er begann zu fürchten, es könnte die Lehre von der Progression der Gebirgsarten einen Stoss erhalten. Zwar glaubte er noch iiber diese Bedenken einigermaassen hinwegzukommen, indem er annahm $(1,337)$, der Porphyr könne an die Stelle des Uebergangsgebirges treten und, in Allgemeinen die Grenze zwischen Ur- und Flötzgebirge einnehmend, sich seinen Lagerungsverhältnissen nach enger an letzteres als an ersteres anschliessen. Aber auch dann blieb es ihm noch wunderbar, dass man da, wo man "die fast schon durchaus mechanischen Bildungen der Uebergangsgebirgsarten" erwarte, statt deren „die krystallerfïllte Masse des Porphyrs" antreffe. Und so empfand er hier die in der Progressionslehre liegende Fessel bereits zu lebhaft, als dass er sie noch lange hätte tragen können.

Auf seine bisherigen Untersuchungen in den Alpen gestlutzt, stellte sich Buch schon damals eine Aufgabe, welche ihn und andere Forscher seitdem vielfach beschäftigt hat, die Aufgabe ein allgemèines Alpenprofil zu entwerfen. Er hatte die Einheit des Gebirges, die Zusammengehörigkeit seiner' Theile erkannt. Es musste ein Gesetz bei der Bildung desselben geherrscht haben. Dieses Gesetz musste sich herausstellen, wenn man zwei hinlänglich von einander entfernte Querdurchschnitte dureh das Gebirge verglich und dabei das Wiederkehrende von den Localen sonderte. Es war dies eine Art der Unter- 
suchung, welche Niemand besser als er mit seiner glänzenden Combinationsgabe ausfithren konnte. Saussure's Beobachtungen am Mont-Cénis und die seinigen am Brenner zum Grunde legend, hob er schon damals (I, 307-328) mehrere Hauptziige der Alpenstructur hervor. Es wurde der allgemeine Charakter der Alpenpässe vortrefflich geschildert, in der Centralkette das Vorherrschen des Glimmerschiefers und die Beschränkung des Granits auf einzelne denselben überragende Massen hervorgehoben, in den Nebenketten die Uebereinstimmung und die Verschiedenheit, welche sich von der nördlichen zur südlichen und in jeder derselben von einem Querdurchschnitt zum anderen nachweisen lassen, besprochen, endlich eine Anzahl von Erscheinungen, die sich auf das Vorkommen der einzelnen Gesteine beziehen, wiederum durch die Richtung der'Gestein absetzenden Fluthen erklärt.

Sowohl die geologische Darstellung wie die durchweg damit verwebte Schilderung des landschaftlichen Charakters der durchforschten Gegenden sind in den besprochenen Abhandlungen von unnachahmlicher Lebendigkeit und reissen durch die Frische und Unmittelbarkeit des Ausdrucks den Leser zur Bewunderung hin.

Auf seiner Wanderuıg von Trient nach Venedig hatte Buch zwei den Alpen stidlich vorliegende Hügelgruppen rechts liegen lassen, deren Kenntniss ihm fur die Vergleichung mit deutschen Vorkommnissen von grosser Wichtigkeit war, die Berischen Hiigel bei Vicenza und die Euganeischen bei Padua. Da Venetien in Augenblick ruhig genug war, um dem Forscher eine freie Bewegung zu gestatten, die sofortige Weiterreise nach Unter-Italien aber auf neue Hindernisse stiess, so unternahm Buch, das Versäumte nachzuholen, einen Ausflug nach jenen Hügeln, wo èr den Basalt unter ähnlichen Verhältnissen wie in Deutschland antraf und schon die Hoffnung zu nähren anfing, seine Beobachtungen in Italien würden ihm lediglich die Bestätigung aller seiner bisherigen Ansichten gewähren. Einen Bericht uber diesen Ausflug, der bis Verona ausgedehnt wurde, hat Buch nicht hinterlassen, indess die Hinweisungen auf die Hügel von Padua und Vicenza, denen wir in mehreren seiner späteren Schriften begegnen, beruhen auf den damals gewonnenen Anschauungen.

Nach der Lagunenstadt zuriickgekehrt, verliess er dieselbe im Anfange des Juni 1798 auf's Neue und erreichte über Ferrara und Bologna am 20. Juni Florenz, am 6. Juli die Ufer des Tiber. 
Sein Aufenthalt in Rom war aber in mehreren Beziehungen ein peinlicher. Einerseits wurde daselbst seine Geduld auf eine harte Probe gestellt, denn dem Ziel seiner Wünsche, dem Vesuv, nahe, konnte er denselben nicht erreichen, weil Neapel, wo der Feldzug gegen die in Rom stehenden Franzosen sich vorbereitete, jedem Fremden verschlossen war. Andererseits salı er bei den zahlreichen Untersuchungen, welche er über den Boden Roins und seiner weiteren Umgebungen anstellte, neue Zweifel an der Werner'schen Lehre in sich auftauchen. Ja es handelte sich jetzt um die wichtigsten, bestrittensten Punkte derselben, un die Entstehungsweise des Basalts und die Bedeutung der Vulkane.

Der Kampf, den er hier zwischen seiuer Anhänglichkeit an die Grundsätze des verehrten Lehrers und seiner neu aufgehenden Ueberzeugung zu bestehen hatte, die Rathlosigkeit, in die er durch diesen Zwiespalt gebracht wurde, spricht sich in den oft angeführten Worten aus, welche er, während ihm Neapel immer noch unzugänglich war, von Rom aus an Moll richtete $(\mathrm{I}, \mathscr{\bigcup})$ ): ${ }_{n}$ Ich suche mich hier so vicl möglich zu entschädigen und streife in den Gegenden umher. Aber jeden Tag fühle ich mehr, dass ich nur halbe Beobachtungen mache. Ich verwirre mich in die Widersprtiche, die hier die Natur mit sich selbst zu machen scheint, und gewiss, es ist kein angenehmes Gefühl, ein Gefühl, das meine körperliche Constitution angreift, am Ende gestehen zu müssen, man wisse nicht, was man glauben soll; oft, ob es erlaubt sei, seineu eigenen Augen zu trauen."

Beinahe acht Monate musste Buch in Rom ausharren. „Zwei Tage am Vesuv," schrieb er in demselben Briefe an Moll, „würden Alles zum Ziel bringen." Schon war er darauf gefasst, unverrichteter Sache umzukehren. Endlich, als im Anfange des Jahres 1799 Neapel vor der französischen Armee die Thoro hatte öffnen müssen, konnte Buch daselbst am 19. Februar seine Beobachtungen beginnen. Aber scine Zweifel wurden nicht so schnell, wie er gehofft hatte, gelöst. Noch im Jahre 1799 sehrieb er an Gilbert in Leilzig: „Ich werde meine Freunde selır täuschen, die glauben, dass, nachdem ich einen Vulkan, wenngleich nur fliichtig, gesehen habe, ich jetzt tiber die verschiedenen Meinungen von unserm Basalt etwas Bestimmtes zu sagen im Stande bin."

Gern würde Buch, nachdem er acht Wochen in Neapel zugebracht hatte, seinen dortigen Aufenthalt noch verlängert haben, hätte nicht 
der weitere Verlauf der in jenen bewegten Jahren schnell auf einander folgenden Zeitereignisse ihn daran verhindert. Während der Krieg wieder in Ober-Italien wüthete, der Aufbruch Macdonald's aus Neapel bevorstand und in Unter-Italien die immer mehr hervortretende Bestrebung die unter französischem Einfluss geschaffenen $\mathrm{Zu}-$ stände zu beseitigen neue heftige Kämpfe vorhersehen liess, wurde ein weiteres Verbleiben daselbst für Buch unmöglich. In der zweiten Hälfte des April trat er seine Rückreise nach dem Norden an, auf welcher er am 5. Mai nach Genua gelangte.

Ueber die Ergebnisse dieser seiner ersten italienischen Reise hat Buch in den Jahren 1799 bis 1801 drei Abhandlungen verfasst. Es sind seine Arbeit ither den Leucit, seine geognostische Uebersicht üher die Gegend von Rom, seine Briefe aus Neapel.

Durch die Feinheit und Neuheit der Untersuchungen, welche er in einem ihm ganz fremden Beobachtungsgebiete ausführte, dureh die untibertrefflichen, tiberall Begeisterung athmenden Schilderungen des Eindrucks, welchen die südliche Natur und das sïdliche Leben auf ihn hervorbrachten, uehmen diese Abhandlungen unter den Arbeiten aus Buch's erster Periode eine hervorragende Stelle ein.

Die erste derselben "sur la formation de la leucite", in de la Métherie's Journal de Physique schon im Jahre 1799 erschienen, gründet sich auf Untersuchungen, welche er theils im Römischen, theils im Neapolitanischen angestellt hat.

Um das Vorkommen des Leucits einerseits in Tuffen und denjenigen basaltischen Gesteinen, denen eine neptunische Entstehung $z u-$ geschrieben wurde, andererseits in entschiedenen Laven mit einander in Uebereinstimmung zu bringen, hatte man angenommen, dass die Krystalle dieses Minerals, welche sich in Laven finden, in einem neptunisch gebildeten Gesteine präexistirt hätten und aus diesem in die Laven tibergegangen wären, eine Annahme, in welcher die Schwerschmelzbarkeit des Leucits bestärkt hatte.

Buch sah aber nicht allein in dem Umstande, dass sich in einigen evidenten Strömen des Vesurs Millionen kleiner Leucite mit wohl erhaltener Form vorfinden, sondern namentlich auch in der Thatsache, dass bei Borghetto, welehes er gemeinschaftlich mit Breislak besuchte, die Leucite häufig einen Kern von Lava einschliessen, sich ałso un- 
möglich früher als diese gebildet haben können, schlagende Widerlegungen jener Annahme. Durch eine Reihe feiner Beobachtungen und sinnreicher Folgerungen gelang ihm der Beweis, dass die Leucite sich aus der Lava während ihres Flusses als Krystalle ausgeschieden haben mussten, also ein vulkanisches Product der Lava selbst seien.

Diese jetzt so geläufige Vorstellungsweise von der Entstehung des Leucits musste damals eine nicht geringe Einwirkung auf die geologische Betrachtung üben. Es wurde klar, dass eine grosse Anzahl basaltähnlicher Massen Unter-Italiens, deren Ursprung bisher streitig gewesen war, durch ihren Leucitgehalt dem Bereich des Vulcanismus anheimfielen. Ja es wurde wahrscheinlich, dass alle Gesteine, die man bisher als unteritalische Basalte bezeichnet batte, auch wenn sie keine erkennbare Leucite enthielten, auf vulkanischem Wege gebildet waren. Und welche Folgen hatte man hieraus flir die Beurtheilung der Basalte iberhaupt zu erwarten?

Buch selbst schrak davor zurück: „Es kann wohl kaum Jemanden geben," schrieb er in dem oben angeführten Briefe an Moll, „der von der Nichtvulkanität des Basaltes so liberzeugt ist als ich; und doch beendige ich eben einen Aufsatz, in dem ich mich in allem Ernste mit vielen noch bisher nicht gesagten Grüden zu zeigen bemühe, dass sich die Leucite, die sich in der grössten Pracht in Roms Ebenen... finden, in einer vulkanisch-fliessenden Masse bildeten."

Die Gefahr, welche dadurch der Werner'schen Lehre drohte, so gut es gehen wollte, abzuwehren, schrieb er unter Anderm an Gilbert (I, 120): „Von dortigen (unteritalienischen) Massen auf die unsrigen (deutschen) zu schliessen, wïrde inmer zu voreilig sein, wenn sie gleich oft täuschende Aehnlichkeit mit dem Basalt haben."

Dieser Vorbehalt hinderte indess nicht, dass Buch's Abhandlung uber den Leucit nicht allein der vulkanistischen Betrachtung des Basalts uberhaupt Vorschub leistete, sondern auch zu mancherlei Fragen hinsichts der Entstehung anderer Gesteine, welche Krystalle porphyrartig einschliessen, ja der Porphyre selbst anregte.

Die zweite der oben genannten Abhandlungen, Buch's geognostische Uebersicht der Gegend von Rom, zuerst 1801 in den Schriften der Gesellschaft naturforschender Freunde zu Berlin, sodann mit einigen Veränderungen in zweiten Baude der Beobachtungen auf Reisen abgedruckt, enthält die Darstellung aller ihrer Altersfolge nach 
geordneten Gebirgsarten, welche in der Umgegend der Stadt entwickelt sind.

Mit den ältesten beginnend, betrachtet er die mannichfaltigen den Apennin zusanmensetzenden Flötzgebirgsarten noch sämmtlich als Aequivalente des Alpenkalks.

Die blauen Thone und gelben Sande, welche die zum Monte Mario aufsteigenden Höhen des linken Tiber-Ufers bilden, fasst er schon sehr richtig als ein von den ubrigen Formationen der Gegend Roms abzutrennendes Ganze auf, dessen organische Reste er als wesentlich verschieden von denen der Apenningesteine erkennt. Es sind Massen, welche später zur tertiären Subapenninformation gestellt worden sind.

Als drittes Glied in der. Altersfolge der römischen Gebirgsarten wird die Basaltformation aufgeführt, welche das Albaner Gebirge und in unmittelbarer Nähe von Rom den Hïgel von Capo di Bove zusammensetzt.

Zwischen dem Apennin, dem erwälnten auf dem linken Tiberufer gelegenen Höhenzuge und den Albaner Gebirge, nahm Buch an, sei ein See vorhanden gewesen, in welchem sich die beiden jtingsten Gesteine der Umgegend Roms, der Tuff und Travertin abgesetzt haben. Die Beschreibung dieser beiden Gebirgsarten bildet den Glanzpunkt der Abhandlung. Buch hatte sich von der vulkanischen Natur vieler Bestandtheile des Tuffs überzeugt, zugleich aber seine Wechsellagerung mit Travertin und seine enge Verbindung mit Geschiebebänken festgestellt. Die Beunruhigung, welche die scheinbar hieriu liegenden Widersprüche anfänglich in ihm hervorgerufen hatten, war nach und nach der Ueberzeugung gewichen, dass die Tuffe, welche den Boden Roms bilden und sich weit durch die römische Campagne verbreiten, aus einem zwar durch Vulkane erzeugten, aber durch die Wasser jenes Sees ausgebreiteten Material beständen. Endlich, die Ansicht Breislak's, dass die Rönischen Hügel selbst die Reste alter Kratere seien, mit entscheidenden Gründen bekämpfend, zeigte er, dass man nicht in der Stadt, sondern feru von derselben, im Albaner Gebirge, die Schlïnde zu suchen habe, aus denen das vulkanische Material der 'Tuffe herrühre. Er führte aus, dass die Römischen Hügel nichts Anderes seien, als ein altes Tiberufer, nach den Ablauf des erwälnten Sees durch die einschneidende Wirkung des Flusses in der allgemeinen Tuffbedeckumg gebildet und durch Wasserrisse, die von der Oberfläche der Tuff bedeckung zu dem Flussthale hinabführen, 
in einzelne Massen zertheilt. Diese Anschauungsweise hat sich durch alle späteren Arbeiten über jenen elassischen Boden bestätigt.

Buch's Briefe aus Neapel, welche die dritte jener Abhandlungen bilden, sind fast ausschliesslich den Ausbruchserscheinungen des Vesuvs gewidmet. Sich auf dic noch frischen Aussagen der Einwohner uber den furchtbaren Ausbruch vou 1794 stïtzend und alle historischen Ueberlieferungen über fribere Eruptionen, aus denen er ein emsiges Studium gemacht hatte, berücksichtigend, gab er von Ereignissen, welche zum Theil so rasch auf einander folgen, dass das Gedächtniss Muhe hat, sie fest zu halten, eine Schilderung, in welcher sie in ihrer gesetzmässigen Reihenfolge, in ihrem Verhältniss von Ursache und Wirkung dargestellt sind.

Wenn die Lavasäule hoch iu den grossen Krater hinaufreicht und das Ausströmen der Dämpfe verhindert, dann ist die Stille da, wie sie dem Gewitter vorangcht. Die erste Kraftäusscrung der noch eingeschlossenen Dämpfe sind die Erdstösse. In den Aufklaffen des Berges mittelst einer am Abhange gebildeten Spalte ron stets radialer Richtung, in der Bildung von kleinen Kratereu, dic sich auf der spalte erheben, daher ebenfalls radial georduet sind, und in dem Ausfluss der Lava aus diesen Krateren sieht er den zweiten Act des grossen Dramas. Wenn die befreiten Dämpfe ausströmen und fein vertheilte Lava vor sich hertreiben, wenn sich in Folge dessen Regenglisse und Aschenregen bilden, beginnt die dritte Thätigkeit. Endlich tritt die vierte und letzte ein mit dem Entstehen der verderblichen Mofetten. Der Krater ist geleert und den Umgebungen des Vulkans ist eine Zeit der Ruhe gesichert, während welcher die Oberfläche der Lavasäule sich allmählich wieder bis zum Gipfel emporhebt.

Ueber die Art, wie sich Buch unmittelbar nach seinem ersten Aufenthalt in Italien den T'heorien gegenüber verhielt, welche sich auf die Ursachen der vulkanischen Thätigkeit beziehen, finden wir in seinen Briefen aus Neapel bemerkenswerthe Andeutungen. „Selbst die befriedigendste dieser Theorien, die Werner'sche der Steinkohlenentztindung," sagt er (I, 434), „muss um so behutsamer angewandt werden, je eimnehmender sie ist. Denn vergebens suchen wir am Vesuv und in der ganzen Gegend umher die Orte, wo diese Steinkohlenflötze könnten gelagert sein. Unter dem Grunde des Meeres? Es ist möglich; aber noch sind keine Erscheinungen gefunden, welche 
die wirkliche Existenz dieser Flötze verbürgen." " "Und wie, wenn es bewiesen wäre," fährt er fort, auf Dolomieu's Nachrichten tuber die Auvergne auspielend, ,.dass die vulkanischen Phänomene primitive Gebirgsarten durchbrächen?* Dass er die Richtigkeit der Werner'schen Anschauungsweise damals ernstlich bezweifelte, geht aus diesen Aeusserungen klar hervor.

Seine Ansicht tiber die Entstehungsart des Vesurs war damals noch die, dass der Berg sich durch successive Lavenergüsse, zum Theil uuter dem Meere, selbst aufgebaut habe. Hebungen des Boden's, wie sie bei grossen Eruptionen an der Küste wahrgenommen worden waren, hatten nach seiner Annahme mitgewirkt, den Vulkan allmählich seine jetzige Höhe über dem Meere erreichen zu lassen (I, 449), doch dachte er mit diesen Hebungen noch keinerlei Veränderungen in der Neigung der Lavabänke verbunden. Die Ideen, welche den Uebergang von seinen alten zu seinen neucn Ueberzeugungen hierüber bilden, tauchten erst später in ihm auf.

Die Briefe aus Neapel lagen zwar, bald nachdem Buch Italien verlassen hatte, druckfertig vor; aber sei es, dass er die darin dargelegten Untersuchungen nicht habe bekannt machen mögen, ohne sie vorher noch ein Mal an Ort und Stelle geprüft zu haben, sei es, dass er die ausgesprochenen Ideen noch habe zurtirkhalten wollen, um das Werner'sche System nicht noch heftiger zu erschitittern, als es namentlich durch seine Abhandlung iiber den Leucit geschehen war; von jenen Briefen veröffentlichte er vorläufig nur einen einzigen in Moll's Jahrbüchern von 1801, weleher, lediglich auf beobachtete Thatsachen bezïglich und alle streitigen Punkte der Vulkanlehre bei Seite lassend, sich gewissermaassen auf neutralem Gebiete bewegt. Es ist sein Brief uber die „Bocche nuove“, eine lebendige Schilderung der damals zum Theil noch dampfenden, fünf Jahre vorher am Abhange des Vesurkegels geöffneten Schlünde und des Eindrucks, welchen die verwistete durch den unverdrossenen Fleiss der Einwohner sich wieder aufrichtende Stadt Torre del Greco hervorbrachte.

Erst nachdem Buch im Jahre 1805 von Neuem am Vesuv gewesen war, entschloss er sich, die ubrigen Briefe im zweiten Bande der Beobachtungen auf Reisen abdrucken zu lassen.

Ehe es aber hierzu kam, veröffentlichte er im Jahre 1801 in der zu Genf erscheinenden Bibliothèque britannique und zwar in Form 
eines Briefes an Pictet, einen der Herausgeber dieser Zeitschrift, seinen Aufsatz "sur les volcans", in dessen erstem Theile er sich, so weit es ihm noch möglich war, von Neuem zu Werner'schen Ansichten ther Basalt und Lava bekanute und seinen damaligen Standpunkt in Betreff der Beurtheilung dieser Gebirgsarten in sehr anziehender Weise darlegte.

Buch hob darin zunächst die von Werner und anderen Geologen aufgestellte Hypothese, dass es zwei dem Stoff nach ibereinstimmende basaltische Gesteine, nämlich einen neptunisch gebildeten Basalt und eine durch Schmelzung daraus entstandene Lava gäbe, hervor. So bald man von dieser Hypothese ausgehe, fligte er hinzu, hörten die Experimente, wodureh der Schotte James Hall die vulkanistischen Theorien seines Landsmanns Hutton zu befestigen suchte, auf, als Widerlegungen der neptunistischen Lehre zu erscheinen. War es dem genannten Mineralogen gelungen, beim Schnelzen von Basalt unter Anwendung einer langsamen Abkühlung eine der ursprünglichen ähnliche Masse zu erzeugen und auf diese Weise der Annahme von der vulkanischen Entstehung des Basalts eine neue Stïtze zu verschaffen, so kebrte jetzt Buch die Waffen desselben gegen ihn und suchte geltend zu machen, die Hall'schen Experimente kämen den Neptunisten mehr als den Vulkanisten zu Statten, indem sie für die Behauptung, dass zwei Gesteine verschiedenen Ursprungs und doch der Masse nach identisch sein können, die Bestätigung gäben. Für die neptunische Entstehung der deutschen Basalte betrachtete Buch das gänzliche Fehlen der Leucite in denselben als einen Beleg. Um das Vorkommen des Augits aber in Beidem, Basalt und Lava, zu erklären, wandte er auf ihn die Vorstellungsweise, welche er in Beziebung auf den Leucit erfolgreich bekämpft hatte, noch an und setzte voraus, die ursprünglich in den Basalten enthaltenen Krystalle dieses Minerals seien bei der Umwandlung desselben in Lava ungeschmolzen geblieben. Die Werner'sche Ansicht, dass die Umschmelzung der Basalte zu Laven durch die fossilen Brennstoffe erzengt werde, welche sich oft mit den Basalten in Verbindung finden, wird zwar hier noch erwähnt, aber nicht mehr ausdrücklich vertheidigt.

Ftir die Zeit, in weleher Buch's Abhandlung "sur les voleans" erschien, hatte sie aber noch dadurch eine besondere Bedeutung, dass in dem zweiten Theil derselben ein kurzer Auszug aus der in den Briefen aus Neapel gegebenen Darstellung der Eruptionsgesetze 
enthalten war, deren Hauptmomente also durch diese Abhandlung zum ersten Male den Geologen mitgetheilt wurden.

Wir haben Buch, nachdem er Neapel verlassen hatte, auf seiner Rlickreise bis Genua begleitet. Von dort ging er um die Mitte des Mai uber Nizza, Marseille und Lyon nach Paris, wo er im Juni 1799 eintraf.

Es ist zu bedauern, dass seine ursprilngliche in Briefen angedeutete Absicht, die Frgebnisse seiner Reise durch die Provence zu veröffentlichen, nicht zur Ausflihrung gekommen ist. Es wlirde von grossem Interesse sein, die Grundsätze der Werner'schen Schule durch Buch auch auf den von dem Schauplatz Werner'scher Thätigkeit so abweichenden französischen Stlden angewandt zu sehen. Aber wie es scheint, stiess eben diese Anwendung auf Schwierigkeiten, welche die beabsichtigte Bekanntmachung verhinderten.

Bei seinem ersten Aufenthalt in Paris hatte Buch den Zwcek, die dortigen Naturforscher und Sammlungen kennen zu lernen. Leider wissen wir wenig iiber die Art, wie er denselben erreichte. Nur sein Umgang mit de la Métherie und Hatiy ist bekannt.

Mit ersterem, dem Autor der théorie de la terre und Herausgeber des Journal de Physique, hatte er vielfache Anknüpfungspunkte. Durch denselben aufgefordert, ihn gegen die Angriffe in Schut\% zu nehmen, welche namentlich von de Luc gegen sein geologisches System gerichtet worden waren, schrieb er an Gilbert (I, 11(1): „die Vertheidigung des Systems, so weit es den Granit angeht, habe ich übernommen, weil es hierin mit meinen, d. b. mit Werner's Ideen ubereinkommt." Bekanntlich hatte de la Métherie den Gedanken ausgesprochen, dass die Granitberge ihre jetzige Gestalt durch die Wirkung der Krystallisationskraft angenommen hätten, so dass jeder derselben gewissermaasen als ein grosser Krystall anzusehen sei, während de Luc diese Berge als stehengebliebene Ueberreste einer zum Theil versunkenen Erdkruste betrachtete, Saussure und Dolomieu sie durch gasförmige Emanationen in die Höhe gehoben dachten (I, 119). Indem Buch in seinen „considérations sur le granit“ der de la Métherie'schen Idee vor denen seiner Widersacher den Vorzug gab $(I, 106)$, knttpfte er an diese Polemik eine Entwickelung seiner damaligen An- 
sichten liber den Granit, welche ein anziehendes Seitenstlick zu seiner Besprechung des Basalts in der Abhandlung nsur les volcans" bildet.

Bemerkenswerth ist darin unter Anderm, dass Buch die Granite der Hochalpen ihrem Alter nach ron denen der Ebene und der niederen Gebirge unterschied und zwar für jünger erklärte. Es sei schon an und für sich wahrscheinlich, sagte er, dass eine Masse, welche sich 1400-2000 Toisen itber die andere erhebt, von neuerer Eutstehung sei als jene (I, 1()3); bei den Hochalpen-Graniten hange diese neuere Entstehuıg nit einer gewöhnlich mehr oler weniger gneusartigen Beschaffenheit derselben zusammen (I, 104). - Aeusserungen uber Altersverschiedenheiten der Granite finden sich zwar auch in Buch's Schriften uber Schlesien, sind indess, insoweit es sich dabei nicht um syenitische, also hornblendehaltige Gesteine, sondern un Hoehalpen-Granite handelt, auf den Entwurf einer geognostischen Beschreibung jener Provinz beschränkt, in wclchen sie woll erst kurz vor der Herausgabe desselben im Jahre 1802 eingeschaltet wurden.

Seine ,considérations sur le granit“ ibergab Buch selbst, ebenso wie seine friber erwïhnte Abbandlung $n$ sur la formation de la leucite“ und seine „considérations sur le baromètre“ (I, 534) an de la Métherie, der sie sämnntlich im 49. Bande seines Journals abdrucken liess.

Welchen Werth Buch darauf legte, mit Haity in persönliche Verbindung zu treten, ergiebt sich aus dem Anfange seines Briefes an Moll vom 3. December 1799: ..Ich habe in Paris Hatiy genau kennen gelernt,: schreibt er daselhst, ..er hat mich mit Gute und Freundschaft überhäuft" $(\mathrm{I}, 121)$. Seine eigenen Arbeiten hatten ihn, wie wir in seiner Abhandlung uber den Kreuzstein sahen, auf Betrachtungen gefuhrt, welche mit den Haily'schen in nahem Zusammenhange standen. Die exacte Behandlungsweise, welche dieser Mineralog in die Krystallkunde einführte, und vermöge welcher er die Formen der Mineralien aus der von ihm angenommenen Primitiv-Form schon im Voraus ableitete, nusste auf Buch einen tiefen Eindruck machen. So nennt er denn auch Haity's kry'stallographisches System in jenem Brief an Moll eine der wichtigsten und merkwürdigsten Erscheinungen des Jabrhunderts und bezeichnet es als Epoche machend in der Geschichte der Physik.

Im August verliess Buch Paris mit der Absicbt, vor seiner Heimkehr die Herbstmonate in Holland zuzubringen und während dieser 
Zneit auch dort die vorhandenen Sammlungen zu studiren. Indess kaum hatte er die holländische Grenze überschritten, als die Landung der Engländer am Helder ihn veranlasste, seinen Plan aufzugeben und uber Gröningen, Aurich, Bremen und Hamburg in das väterliche Haus zurlickzukehren, wo er am 26. September 1799 eintraf.

Den Winter von 1799 auf 1800 verlebte Buch abwechselnd auf Stolpe und zu Berlin, wo er mit Karsten und Klaproth einen lebhaften Verkehr unterhielt.

Inzwischen eröffnete sich ihm die erfreuliche Aussicht, ein Land kennen zu lernen, welches ihı, dem Gebirgsforscher, nicht länger fremd bleiben durfte, die Schweiz. Durch den Minister von Heinitz wurde ihm, seinen Wünschen entsprechend, der Auftrag ertheilt, den Cantou Neuchâtel, welcher mit Preussen eng verbunden war, auf nutzbare Mineralien, namentlich aber die Umgegend von Locle auf das dortige Kohlenvorkommen zu durchforschen, ein Unternehmen, für dessen Zustandekommen Karsten thätig mitwirkte.

Im Mai des Jahres 1800 verliess Buch Berlin und nahm zuerst seinen Weg nach der Grafschaft Mark, um sich in deu dortigen Kohlenrevier Htilfsquellen für die etwa bei Locle nöthigen Versuchs- und Gewinnungs-Arbeiten zu eröffnen. Sodann ging er nach Cöln, den Rhein hinauf nach Basel und von dort nach seinem Bestinmungsort.

Hier machte er sich, begiinstigt durch die Theilnahme des damaligen Gouverneurs de Beville, sogleich an seine Aufgabe. So sehen wir ihn noch einmal emsig als Bergmann beschäftigt. Mit Bohrzeug, das er sich aus Deutschland hatte kommen lassen, wurde unter seiner Anleitung bei Locle dem gesuchten Brennstoffe nachgegangen. Zugleich widmete er den Asphalten, den Gypsen, so wie Allem, was fitr die Industrie des Landes Vortheil versprach, eine dauernde Aufmerksamkeit.

Die zweite Hälfte des Jahres 1800, das ganze Jahr 1801 und den Anfaug des Jahres 1802 verlebte Buch in Neuchâtel und dessen Umgebungen fast ohne Unterbrechung. Nur die benachbarten wissenschaftlichen Mittelpunkte der Schweiz besuchte er während dieser Zeit auf wenige Tage, Bern schon im Juli 1800, um sich mit Tralles, dessen geodätische Arbeiten für ihn von Wichtigkeit waren, in Verbindung zu setzen, Genf im September desselben Jahres, sowie im Fruhjahr 1801, um dio zahlreichen wissenschaftlich hervorragenden 
Männer, welche daselbst lebten, kennen zu lernen. Mit seiner ersten Anwesenheit in Genf verband er einen kurzen Ausflug nach Chamouni, mit der zweiten einc Besichtigung der Ungebungen von Salins in Frankreich.

Erst voin Jahre 1802 an unterbrach er seinen Aufenthalt in Neuchâtel durch grössere Unternehmungen. Da cr aber von denselben immer wieder dahin zurïckkehrte, ohue inzwischen seine Heimath gesehen zu haben, so kann man sagen, dass Buch beiuahe drei Jahre lang Neuchâtel zu seinem Wohnsitz gemacht habe.

Diese Zeit gewährte ihm ausser ciner reichen wissenschaftlichen Erndte auch eine lebhafte Befriedigung dureh die freundlichen Beziehungen, in welche er zu den ersten dortigen Familien trat. Die Ehrenhaftigkeit und der calvinistische Ernst, den er bei ilınen fand, verbunden mit einer feinen Bildung in Ungang und Sprache, sagten ihm entschieden $\mathrm{zu}$, während seine Frische und Lebendigkeit ein günstiges Element in jene Kreise hineintrugen und ihm eine grosse Beliebtheit in denselben verschafften. Nach seinen Ausflïgen pflegte cr den Alend im Hause der Montmollin's, Sandoz's, Chambrier's, Yvernois's, Dardel's zuzubringen, so dass Arbeit und edler Lebensgenuss in gliickliebster Weise mit einander abwechselten.

Die erste grössere Unternehmung, die cr von Neuchâtel aus in Jahre 1802 ausführte, scine berühmte, in Bricfen an Karsten geschilderte Reise in die Auvergne, nimmt eine wichtige Stelle in der Geschichte seines Abfalls von der Werner'schen Lelre und der Entstehung der ihm eigenthïmlichen Ideen ein.

Dolomieu's Behauptung, dass dic auvergner Vulkanc aus dem Granit hervorbrächen, stimmte mit den Theorien Werner's nicht iiberein und blieb im Allgemeinen bei den Anhängern derselben unberiicksichtigt. Indess kam sie von zu achtbarer Quclle und war mit zu grosser Zuversicht ausgesprochen, als dass Buch vicht hitte das Bedürfniss empfinden sollen, sich an Ort und Stelle von ihrer Richtigkeit oder Unrichtigkeit zu überzeugen.

Buch fand bei seinem ersten Eintritt in dic Auvergne, dass dic Dolomicu'sche Behauptung sich auf's Vollkommenste bestätigte. Der Widerspruch, in den die Werner'sche Jehre dadurch mit sich selbst gericth, war unlösbar; denn waren die auf dem Granit stehenden Vulkane in der That durch fossile Brennstoffe erzeugt, so hätten diese 
unter dem Granit liegen müssen, was wiederum nach Werner'schen Grundsätzen, wonach der Granit als die unterste Gebirgsart angesehen wurde, nicht der Fall sein konnte. Hatte er schon am Vesuv die Kohlenlager vergeblich gesucht, die dessen unterirdisches Feuer hätten unterhalten können, so gab er hier den Gedanken an eine solche Ursache der vulkanischen Phänomene für immer auf.

Aber bei diesem negativen Resultat blieb er nicht stehen. Durch dic Betrachtingen, welche er an den Gesteinen der Puys anstellte, gelangte er zu der Ansicht, die auvergner Laven, die aus dem Granit hervorgebrochen sind, scien auch aus demselben entstanden (I, 487), sie seien nichts Anderes als ein durch eine unterirdische Wärmequelle und unte: Mitwirkung chemischer Agentien in Fluss gerathener Granit. In dem Gestein des Puy de Dôme und einiger anderer demselben benachbarter Berge, welches er vortrefflich beschrieb und als eine eigene dem Trapp-Porphyr verwandte Gebirgsart mit dem Namen Domit belegte $(I, 478)$, während es heute den im weiteren Sinne aufgefassten Trachyten zugerechnet wird, glaubte er eine Zwischenstufe zwischen dem Granit und der Lava, einen etwa durch unvollständige Schmelzung und Einwirkung von Dämpfen aufgeblähten und gelockerten Granit erkannt zu haben. Wic er am Puy de Chopine den Uebergang von Granit in Domit nachweisen zu können glaubte, so am Puy de la Nugère den Uebergang von Domit in Lava. „Der Granit ist durch eine Reihe verschiedenartiger Operationen zu Lava verändert, “ ruft er bei Betrachtung des letztgenannten Vulkans aus (I, 487).

An den Domit kniipfte Buch noch eine Reihe von Reflexionen, welche seinen Briefen aus der Auvergne eine grosse Bedeutung geben. Die Beschaffenheit dieses Gestcins und die regelmässige Kuppelform der aus denselben bestehenden Berge hatten in ihm die Ueberzeugung hervorgerufen, alle Domitkegel seicn "durch die innere vulkanische Kraft in die Höhe geboben," und die Vorstellung erweckt, sie könnten sich wie Blasen, dic olne sich zu öffnen „auf ciner viscosen Flïssigkeit" aufsteigen, gebildet haben (I, 481-483). Wenn er aber, im Verfolg seiner auvergner Briefe zum Montdore ibergehend, die Frage aufwirft, was verhindern könne, die Montdore-Porphyre ebenso entstanden und ${ }_{n}$ in die Höhe gehoben" zu denken wie die Domite und daraus die "Neigung der Schichten vom Mittelpunkte der Erhebung“ zu erklären; wenn er weiter fragt, ob nicht der ganze Cireus des Montdore eine Einstiirzung sei, die cinen früheren Krater verwischte, 


\section{XXXVI}

eine Einstürzung, die nach vorhergegangener Erhebung des Berges um so begreiflicher wäre (I, 515), so wird man nicht umlin können, in diesen Aeusserungen, aus denen die Annalme einer Aufrichtung der Bänke gegen das Centrum des Berges klar hervortritt, den Kein seiner Theorie der Erhebungskratere zu erkennen, welcher demnach, wie auch Naumann in seinem Lehrbuch der Geologie ausspricht. sehon in den Briefen aus der Auvergne enthalten ist. Aber wie jene Annahıne wesentlich von der Betrachtung trachytiseher Gesteine ausging und mit Bucl's damaligen Ansichten iiber die Entstehungsweise derselben in unmittelbarem Zusammenhang stand, so wurde sie von ihm zu jener Zeit auch nur auf trachytische Kegel augewandt. Denn wenn Buch in den Briefen aus der Auvergne auch schon vielfach Analogien zwischen den aurergner und italienischen Vulkanen andeutet, wenn er aucb, nachdem er schr richtig die aus S'chlacken gebildeten Puys tiber Clermont mit den Bocehe nuove und viuli am Vesuv, mit dem Monte Rosso am Aetna verglichen hat, hinzufigt: .,aber wo ist der Vesuv oder Actna selbst, dem diese untergeordneten Kegel gehorehen? Sollte es der Montdore sein?" (I, 49)6), so verging doch noch eine geraume Zeit, bis er die Entstehung des Vesuv und Montdore auf ein gemeinsames Princip zuriiekfithrte.

Nicht allein auf Buch's Ansicht iiber die Vulkane, sondern auch auf die tiber den Basalt musste seine Reise nach der Auvergne Einfluss uben. Nachdem er alle Gesteine, welche aus nachweisbaren Krateren geflossen sind und als sehmale Ströme die Thäler erfillt haben, zur Lava gestellt hatte, blieben ihm die deckenartig ausgebreiteten Basaltmassen uibrig, wclehe grosse Flächen in dem von ihm bereisten Theile der Auvergne iiberzichen. Dass er auch diese Basalt de cken, in deren Lagerungsverhältnissen er Analogien mit manchen deutsehen Basaltvorkommnissen nicht verkennen komnte, solcher Analogien ungeachtet schon als vulkanisch entstanden betrachtete, geht aus zahlreichen Stellen seiner auvergner Briefe hervor. Und wenn er schliesslich auch hier die deutsehen Basalte noch denı Neptunismus retten will; wenn er daran crinnert, dass in Deutschland „viele Gebirgsarten, deren Entstehung mit vulkanistischen Ideen gar nicht vereinbar ist", „des Basalts wesentliche Begleiter sind", und dass eine eigene Kohlenformation daselbst ganz von basaltischen Gesteinen umschlossen vorkomnt (I, 517); wenn er die Warnung ergehen lässt, auch die eifrigsten Plutonisten sollten es nicht wagen, die in der Auvergne 
erhaltenen Resultate auf die deutschen Basalte anzuwenden (I, 518), so leuchtet doch ein, dass der Sehritt, der zur vulkanistischen Betrachtung aller Basalte zu thun blieb, nicht mehr lange auf sich warten lassen konnte.

In Beziehung auf die Darstellung geniessen Buch's Briefe aus der Auvergne der Vorziige, welche alle seine Schriften auszeichnen, in hohem Maasse. Indem die beigebrachten Thatsachen lediglich zur Verfolgung der vorgesteckten Ziele verwandt werden, indem hiermit eine allgemeine Schilderung des Landes verbunden wird, welche, mag sie der von den Krateren ausgehenden Verwlistung, mag sie dem reichen Aubau der Limagne gelten, inımer in wenigen Zitgen den Eindruck der Landschaft wiedergiebt, entsteht ein Ganzes, das den Namen eines Kunstwerks verdient und den Freund von Naturschilderungen unwiderstehlich fesselt.

Buch's Reise in dic Auvergue war in April angetreten, im Mai bereits vollendet. In der unglaublich kurzen Zeit von einigen Wochen ist das Beobachtungsmaterial gewonnen worden, welches dieser bedeutenden Arbeit zum Grunde liegt.

Die aus Clermont datirten Briefe wurden schon im Januar und Februar 1804 durch Karsten der Gesellschaft naturforschender Freunde zu Berlin mitgetheilt, die den Montdore behandelnden vollendete er in demselbeu Jahre in Schlesien und in Berlin. Sämmtlich sind sie also vor seiner zweiten italienischen Reise verfasst, so dass diese keinen Einfluss darauf ausgeiilt haben kann. Veröffentlicht wurden dieselben zum ersten Male im zweiten Bande der Beobachtungen auf Reisen, welcher 1806 gedruckt und 1809 ausgegeben worden ist.

Seine zweite in Sommer 1802 von Neuchâtel aus unternommene Reise trat Buch in den letzten Tagen des Juli an. Er beabsichtigte gemeinsehaftlich mit Struve die Ungegend des St. Gotthard zu durchforschen und vor der Rückkehr nach Neuchâtel einen längeren Aufenthalt in Genf zu nehmen.

In Airolo traf er mit seinem Reisegefährten zusammen, den er als deukenden Naturforscher hochachten lernte. Theils mit ihm, theils allein durchwanderte er das zwischen Dazio, Dissentis und Andermatt liegende Gebirge. Auf einer von ihm allein unternommenen Abschweifung zu den oberitalienischen Seen, auf welcher er 
die Ufer des Lago Maggiore untersachte, dic Umgebungen Luganos bereits liebgewann und in Como einen Besuch bei Volta abstattete, gelangte er bis nach Mailand, woselbst er mit Breislak uud Pini verkehrte. Sodann wandte er sich über Domodossola nach der Schweiz zurück und erreichte auf der im Bau begriffenen Simplonstrasse Brieg. Nachdem er hier von Neuem mit Struve zusammengetroffen war, besuchten beide das damals noch wenig gekannte, zur Gebirgsmasse des Monte Rosa aufsteigende Saaser Thal, wo Buch hoch erfieut war, die GabbroGesteine, welche in Schlesien scine Aufmerksamkeit erregt hatten, einen wesentlichen Antheil an der Zusammensetzung des Gebirges nehmen und auf diese Weise als wichtige und selbststinclige krystallinische Gebilde bestätigt zu schen. Ueber Martigny und Bex wurde Lausanne erreicht. Von hier ging Buch allein nach Genf weiter, wo er am 8. September cintraf.

Obgleich er in Genf von der Prévost-Pictet'schen Familie mit Beweisen aufopferuder Freundschaft aufigenommen wurde, obgleich

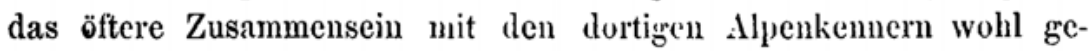
eignet gewesen wäre, ihn zu fiesseln, zog es ihn doch, nach zweimonatlichem Verweilen daselbst, nach Neuchâtel zuriick. „Genève instruit, Neuchâtel attache, " pflegte er zu sagen.

Hier verlebte er den Rest des Winters in den ihm lieb gewordenen Kreisen, welche durch die Ankunft des aus Bern iibergesiedelten Tralles einen ihm wichtigen Zuwachs erhalten hatten. Mit demselben unterhiclt er in Beziehung auf physikalische und meteorologisehe Fragen, welche ihn auch in Neuchâtel neben seinen geologischen Untersuchungen beschäftigten, eine lebhafte Verloindung, und auf's Wärmste interessirte er sich für die Verhandlungen, welche darauf grerichtet waren, diesen Physiker für die Berliner Akadenie der Wissenschaften zu gewinnen.

Ebenso hatte er an Osterwald, dessen kartographische Arbeiten nit seinen eigenen geologischen in enger Beziehung standen, einen für ihn erfreulichen Anhalt.

An den wöchentlichen Vereinigungen aller in Neuchâtel si h wissenschaftlich beschäftigenden Mïmer nahm er regen Antheil und hielt in denselben bereits über die Ergebnisse seiner in schweizer Jura angestellten Untersuchungen Vorträgc, welche, wic es scheint, zur Ausarbeitung der kleineren in diesem Bande abgedruckten Auf- 
sätze über den Jura, das Val de Travers und den Gyps von Boudri Veranlassung gaben.

Nachdem er seine Unternehnungen des Sommers 1803 mit einem Ausfluge nach Bex cröffuet hatte, wo er unter Fiihrung Struve's das von diesem so vielfach untersuchte Salzvorkommen studirte, und nachuen er von dort durch die Freiburger $\mathrm{Al}_{\text {plen }}$ nach Neuchâtel zurbicksekehrt war, verblieb er noch bis zum August in letzterer Stadt, um daselbst seine Arbeiten iiber den geognostischen Bau des Cantons theils durch zalulreiche, von Neuem nach allen kichtungen hin unternommene Wanderungen, theils dureh Niederschreiben der gewonnenen liesultate zu völligem $\Lambda$ bschluss zu bringen.

Ehe Buch Neuchâtel verliess, tibergab er der Stadt als Andenken eine Reihe vou ihm wihhend seines Aufenthalts in der Selıweiz gesammelter Gebirgsarten und einen daza gehörigen Catalog, weleher in scinem IIaupttheile ¿lli Gesteine des Neuchâteller Jura und in seinem einleiteuden Theile 35 Gesteine der Alpen vom St. Gotthard, aus dem Wallis und aus dem Waaltlande bespricht. Vou diesem Catalog, weleher bisher nur in einigen Handschriften vorhanden gewesen ist, hat Studer in seimer vortrefflichen Geschichte der physisehen Geographic der Selnweiz eine Analyse gegeben, in welcher es u. A. heisst: "Eine Beschreibung von 251 Stiicken meist nahe ubereinstimmender Felsarten mag leicht abschreckend erscheinen, aber der Verfasser verbindet sie mit so vielen Bennerkungen iiber den Ursprung der Sehichtenlage, Kettenform, Thalbildung, über die Sisswasserbildung in Locle, den Asphalt in Val-Travers, die Mollasse von Boudri, dass das Interesse stets wach erhalten wird." In Uebereinstimmung hiermit wird man es gerechtfertigt finden, dass der Buch'sche Catalog in den ersten Bande von Buch's gesanmelten Schriften abgedruckt wurde. Es konnten zwei Mauuscripte desselben benutzt werden, deren eines von Buch's eigener Hand sich in dessen Nachlass vorgefunden hat, während ein anderes, dem Herrn August von Montmollin gehörig, durch Vermittelung des Herrn Studer nach Berlin gelangte. Letzteres hat dadurch einen besonderen Werth, dass demselben die drei oben erwähnten Aufsätze „sur le Jura“, "sur le Val de 'Travers" und "sur le gypse de Boudri" hinzugefuigt sind, welehe zum Theil wenigstens, die zerstreuten Bemer- 
kungen des Catalogs zusammenfassen und dem erstgenannten Manuseripte fehlen.

Nachdem Buch in dem cinleitenden Theile des Catalogs Gelegenheit genommen hat, verschiedene Ergebnisse seiner jiingsten Alpenreisen aufzuzeichnen, bringt er in Haupteatalog vorzugsweise das Alter und die Beschaffenheit der den Jura bildenden Gesteine; die Structur seiner Ketten, endlich das Vorkommen der Blöcke von alpinen Felsarten an seinem Abhange zur Sprache.

In Betreff der den Jura zusammensetzenden Gestcine, denen auch der Aufsatz "sur le Jura" gewidmet ist, war Buch damals der Meinung, dass, während die Alpen eine einfache Reihe der Fornationen vom Granit bis in den Alpenkalk darstellen, diese Reihe sich im Jura durch den Beginn einer neueren Formation fortsetze, und letzteres Gebirge lediglich als ein Theil der Alpen, als eine Anzahl iutsserer Ketten derselben anzusehen sei. Um dic Zusammensetzung dieser neueren Formation zu erforschen, hatte sich Buch die schwierige Aufgabe gestellt, die Aufeinanderfolge ihrer Bänke bis beinahe Tausend an der Zahl zu ermitteln. In diese Folge ordnete er alle Gesteinsvorkommnisse bis zum Chasseral, zun Doubs und zum oberen Val de Travers nit äusserster Sorgfalt ein. Die compacten, die körnigen, die oolithischen und mergligen, die einzelnen versteinerungsflihreuden Bänke, welche er in geschicktester Weise zur Orientirung in dem Labyrinth der Juraketten anwandte, konnten danials noch nicht in ibrem Verhältniss zu den Hauptabtheilungen der Juraformation und namentlich zu den in seinen späteren wichtigen Arbeiten von ihm als weisser und brauner Jura bezeichneten Schichtensystenen aufgefasst werden. Dagegen gelang es seinem Scharfblick, die am Neuchâteller See entwickelten gelben Kalke und; blauen Thone, sowie die damit tubereinstimmenden asphaltreichen Bänke des Val de Travers als ein besonderes Schichtensystem von den übrigen dortigen Gesteinen zu trennen. Es sind die Bildungen, welche wir heute unter dem Namen des Néocomien als die untersten der Kreideformation ansehen.

Ueber die Structur der Juraketten hat Buch in seinen Catalog und seine Abhandlung über das Val de Travers werthvolle Beobachtungen niedergelegt, wenngleich es erst einer späteren Zeit gelang, das Schema hinzustellen, auf welches sich alle Eigenthümlichkeiten jener Ketten in einfachster Weise zurückführen lassen. Beachtenswerth 
ist es, dass in Buch's genannten Arbeiten den Veränderungen, welche die Schichten nach ihrem Absatz in Beziehung auf ihre Neigung erfuhren, schon ein bedeutend grösserer Spielraum eingeräumt ist, als in seinen früheren Schriften. Es wird angenommen, die Bänke, aus denen eine Jurakette zusammengesetzt ist, hätten eine Wippenbewegung (mouvement de bascule) ausgeführt, wobei sich dieselben zur Hälfte gesenkt, zur Hälfte nach der entgegengesetzten Seite in die Höhe gehoben hätten. Indem sich andere Theile derselben Schichten in die durch diese Hebungen erzeugten hohlen Räume gestirzt hätten, wäre das System parallel neben einander verlaufender Ketten, welche das Juragebirge bilden, entstanden. Auf die äusseren Ketten in den Alpen selbst wurde von ihm eine ähnliche Erklärung angewandt.

Das Vorkommen von Blöcken alpiner Gesteine an Abbauge des Jura beschäftigte Buch schon damals schr lebhaft, wie aus den zahlreichen Daten, welche er dariiber gesammelt hat, hervorgeht. Sieh der Saussure'schen Hypothese auschliessend leitete er ihre Zerstreuung von einer Fluth ab, welche sich dureh das Rhonethal von den Alpen gegen den Jura gewälzt hätte $(1, c(j \bar{t})$. Den plötzlichen Ausbruch dieser Fluth erklärte er durch den Einsturz der Gebirgsmasse, vermittelst deren nach ihm die Dent de Morcles und Dent du Midi einst mit einander zusammengehangen hätten, und dureh die Entlecrung. der dahinter aufgestaut gewesenen Gewässer des Wallis (I, 670). Die von dieser Fluth verbreiteten Granite leitete er mit Saussure von dem östlichen Ende der Montblanc-Kette und zwar von der Pointe d'Ornex ab, wo Murrith sie hatte anstehen sehen (I, 671 u. 672). GabbroGesteine hatte er zwar, wie oben besprochen wurde, mit Struve am Monte Rosa gefunden, aber er hiclt es futr sehr unwahrscheinlich, dass dieselben den winkligen Weg aus den Thälern von St. Nicolas und Saas bis zur Rhone, das Wallis herunter bis Martigny und von da bis zum Jura zurückgelegt hảben sollten; er war der Meinung, es mitssten deren auch näher bei Martigny, etwa im Hintergrunde des Val de Bagne austehen (I, 682), von wo sie einen kürzeren und geraderen Weg bis zu ihren jetzigen Plätzen gehabt haben würden. Später kam Buch bekanntlich noch mehrere Male auf die Zerstreuung der alpinen Blöcke zurück, um seine Ansicht darüber mit seinen späteren Annahmen über die Entstehungsweise der Alpen in Einklang zu bringen.

Um das Bild der reichen literarischen Thätigkeit, welche Buch 
während seines Aufenthalts in der Sehweiz entwickelte, zu vervollständigen, ist es nöthig zu erwälıuen, dass er zu Neuchâtel den in der Bibliothèque britaunique veröffentlichten Aufsatz verfasste, in wclchem er die Controverse zwischen Kirwan und James Hall iber die Bildungsweise des Granits besprach und fitr Kirwan, also noch einmal für die neptunische Bildung dieser Gebirgsart Partei ergriff; dass er ebenfalls zu Neuchâtel seine bereits oben erwähnten Abhandlungen über die Vulkanc sowie über dic Vergleichung zwischen Brenner und Mont Cénis niederselırieb; dass er hier den ersten Band seiner Beobachtungen auf Reisen für den Druek vorbereitete und mit jener in so warmen Worten gehaltenen Zueignung an Werner versab; dass endlich von physikalischen Arbeiten daselbst sein Brief an Pietet "sur la temperature de quelques sources des environs de Neuchâtel" entstand. In demselben führte er durch, dass die von ilım an einigen Quclleu des Jura beobachtete niedrige Temperatur nielt etwa mit dem Vorhandensein der Eisgrutten in diesem Gebirge, sondern mit der niedrigen mittleren Temperatur zusanmenhange, welche die Jurathäler auszcicline und merklich geringer sei als die Erhebung derselben ïber den Meere allein würde erwarten lassen.

Nach sciner Abreise von Neuchâtel wolltẹ Buch die Schweiz nicht verlassen, ohne dass er sich vorher mit den vielfachen Erfahrungen, welehe er daselbst gesammelt hatte, vou Neuen an der Lösung der Aufgabe versucht hätte, den Bau der Alpen an einem Querdurehschnitt dureh dieselben zur Darstellung zu bringen. Der Durchsehnitt, welchen er jetzt hicrzu wählte, war durch die Gebirge der üstlichen Schwciz gelegt, denen er während des Herbstes eine genaue und eingehende Untersuchung widmete. Buch schricb zwar unmittelbar nach seiner Heimkehr iiber die Ergebnisse dieser Lntersuchung eine Abliandlung, welche er „Reise über die Gebirgszüge der Alpeu zuvischen Glarus und Chiavenna" betitelte, und in welcher er ausfuihrte, dass die Construction der Alpen mit den allgemeinen geognostischen Gesetzen in vollstïndigem Einkling stehe; auch theilte er diese Ergebnisse, auf welche er grossen Werth legte, schon in Winter von 180:3 auf 1804 der Gesellschaft naturforschender Freunde zu Berlin mit. Da er sie jedoch erst vicl später (im Jahre 1809) veröffentlichte, da dieselben also erst im zweiten Bande seiner gesantmelten Schriften zum Abdruck kommen werden, und da sich endlich 
auch Erörterungen daran angeknïpft baben, welche diesem spüteren Jahre angehören, so wird davon erst im weiteren Verfolg dieser Lebensskizze ausführlicher die Rede sein.

Im Winter von 1803 auf 1804, während Buch sich in Berlin aufhielt, wurde er vom Grafen Reden, dem Nachfolger des Ministers von Heinitz aufgefordert, seine Untersuchungen in Schlesien von Neuem aufzunehmen. Buch hatte damals vor, in die Provenee und nach Nizza zu gehen, wo er auf der Rüekreise ausıItalien nur flüchtige Beobachtungen hatte anstellen können, und Graf Reden nahm es hoch auf, dass er die Ausftihrung dieses Plans zu Gunsten der Fortsetzung seiner schlesischen Arbeiten verschob.

Am 5. Mai 1804 verliess Buch Berlin, jedoch nicht, um sich direct nach Schlesien zu begeben, sondern vorher einen Besuch bei Werner abzustatten, was er nach seinem Abgange von der Freiberger Akademie mehrmals gethan, jetzt aber wegen seiner längeren Abwesenheit von Deutschland seit Jahren unterlassen hatte. Werner hatte von Frankreich her und zwar dureh de la Metherie Kunde von Buch's Ansichten über die Gebirge der Auvergne erhalten. Buch wusste, dass er in Freiberg bereits als Apostat bctrachtet würde. Es gehörte seine Pietät für den Meister und seine in allen Lebensverhältnissen bewiesene männliehe Gesinnung dazu, um Freiberg im damaligen Augenblicke nicht zu umgehen, sondern aufzusuchen. Auch sehcint Werner dies anerkannt zu haben, indem er ihn wie einen Soln empfing und nicht duldete, dass er anders als vormals in seinem Hause wohnte. Es konnte nicht fehlen, dass Werner sich einen Theile der Buch'schen Ansichten lebhaft entgegenstellte; namentlich erklïrte er sich auf das Entschicdenste gegen dic Annahme der Umwandlung des Granits in Lava und gegen die 'Theorie der Entstehung der MontdorePorphyre; doch wurde ein förmlicher Bruch von beiden Seiten gliucklich vermieden und Buch verliess Freiberg leichteren Herzens nach einem mehrtägigen Aufenthalt daselbst.

In der Mitte des Mai befand sich Buch bereits in Schlesien. Es scheint, dass ilım daselbst die Aufgabe gestellt war, sowohl unter Benutzung vorhandener Bezirks-Aufnahmen und Grubenrisse geoguostisehe Specialkarten von einzelnen schon frïher von ihm bereisten, in berg- 
männischer Hinsicht wichtigen Districten zu entwerfen, als auch seine Untersuchungen auf die ihm noch unbekannt gebliebenen Theile der Provinz auszudehneu. Nachdem er seine Arbeiten in der Grafschaft Glatz und den angrenzenden Gebieten Obersehlesiens begonnen hatte, setzte er dieselben im niederschlesischen Gebirge fort, wo der Graf Reden und Karsten sich im Interesse des schlesischen Bergbaues längere Zeit aufhielten und Buch an den Berathungen derselben eifrigen Antheil nahm. Am Ende des August trat Karsten eine Reise nach Wien an, und da Buch, obgleich ihm auf Anordnung des Ministers die Itillfsmittel zur Verfolgung seiner Zwecke reichlich zuflossen, doch bald erkenuen musste, dass er diese Zwecke in der von ihm dafür bestimnten Zeit nicht so, wie er es wünschte, würde erreichen können, so entschloss er sich Schlesien wieder zu verlassen und Karsten auf dessen Wunsch zu begleiten. Inless au der Landesgrenze erwiesen sich seine Papiere als unzureichend, und die Verzögerung, welche dadurch veraulasst wurde, vereitelte seine Wiedervereinigung nit Karsten, was er besonders schmerzlich empfand, als er erfuhr, dass dieser mit seiner Reise einen längeren Aufenthalt in den Alpen von Kärnthen und Krain verbände. Die ihm auf solche Weise gegen seinen Willen für seine schlesischen Untersuchungen zurückgegebene Zeit benutzte Buch wälırend des Septemhers, die vom Grafen Reden gewuinschte Durchforschung Neu-Schlesiens auszuführen. Nachdem er hierauf den Minister auf einer Rundreise durch die ober. schlesischen Bergwerksdistricte und einen Theil des damaligen Sudpreussens begleitet hatte, auf welcher er der Gegend von Tarnowitz, Kreuzburg und Panki besondere Aufmerksamkeit widmete, kehrte er Ende Octobers nach Berlin zurïck.

Das hinterlassene Ergebniss seines zweiten schlesischen Aufenthalts besteht in mehreren handschriftlichen Berichten, welche er dem Grafen Reden uberreichte. Der umfassendste derselben ist seine ,geognostische Uebersicht von Neuschlesien," die erste Arbeit, in welcher genauere Nachrichten über diesen jetzt zum Königreich Polen gehörenden Landstrich gegeben wurden, und interessant durch die Darstellung des dortigen Flötzgebirges, welches die Fortsetzung des oberschlesischen bildet. Nach einander besprach er darin das Steinkohlengebirge der weiteren Umgegend von Bendzin, den erzführenden Muschelkalk, der damals noch als Alpenkalk angesprochen wurde, den davon schon richtig gesonderten Jurakalk, ein neucres kohlen- 
führendes Gebirge, jetzt als jüngere Trias erkannt, endlich jene Eisensteine, in denen zwar bereits Anımoniten aufgefunden waren, ohne jedoch schon als Kennzeichen mittlerer Jurabildungen angesehen werden zu können. Das Steinsalz von Wieliczka, dessen tertiäres Alter jetzt festgestellt ist, wurde damals noch als ein seiner Entstehungszeit nach zwischen beide Kalke einzuschaltendes Gestein betrachtet.

Ein anderer Bericht „über die Ausdehnung des Steinkohlengebirges in Leobschiitzer Kreise“ lieferte zahlreiche Daten üher die Gesteinsvorkommnisse des darin besprochenen Theils von Schlesien.

Beide Arbeiten sowie eine kurze Notiz „tiber Steinkohlenversuche bei Tost" werden in den Acten des Breslauer Oberbergamts aufbewahrt, welehes diesclben in dem ersten Bande von Buch's gesammelten Schriften abzudrucken gestattete.

Nichts wïnschte Buch so sehr, als nach seinen Erfahrungen in der Auvergne zu den Vulkanen Unter-Italiens zuriickzukehren. Die im Sonmer 1805 erhaltene Nachricht, dass Alexander von Humboldt und Gay-Iussac sich von Paris aus dorthin begeben würden, brachte den noch schwankenden Entschluss zu einer zweiten Reise nach Neapel in ihm zur Entscheidung.

In Rom traf er am 5. Juli mit diesen Forschern zusammen und wohnte mit ihnen im Palazzo Tommati, den Wilhelm von Humboldt, damals preussischer Gesandter am päpstlichen Stuhl, inne hatte. Es war das erste Mal, dass er seinen berïhmten Landsmann nach dessen Riickkehr aus America wiedersah; begeistert vernahm er von ihm die Schilderungen von den grossartigen vulkanischen Erscheinungen der anderen Hemisphäre; die vielfachen Analogien, welche er zwischen diesen und denen der alten Welt entdeckte, gaben ihm die befriedigende Gewissheit, dass die Folgerungen, die er aus seinen Beobachtungen gezogen hatte, sich als allgemeinguiltig herausstellen wïrden.

Buch benutzte seinen Aufenthalt in Rom dazu, durch zahlreiche Ausflitige in die Umge gend seine vor sechs Jahren gemachten Untersuchungen zu ergänzen. Die tibrige Zeit wurde den römischen Alterthitimern und Kunstschätzen gewidmet. Der Umgang mit dem :ilteren Humboldt,der sich willig zur Futhrung durch das ihm so wohlbekannte alte Rom erbot, und der Zusammenfluss bedeutender Künstler im Hum- 
boldt'schen Hause, unter denen sich Rauch und Thorwaldsen befanden, gab dazu eine Anregung, deren es für Buch kaum bedurfte.

$\Lambda \mathrm{m}$ 6. Juni traten die drei Forscher die Reise nach Neapel an. Mit der freudigsten Empfindung sahen sie schon in Gaëta den Feuerschein des Berges zu sich herüberleuchten. Am 17. hatten sie sich bereits in der Crocella jenseits Santa Lucia niedergelassen.

Der Zufall wollte, dass ihr kurzer Aufenthalt in Neapel nit einem der stiirksten Erdbeben, deren sieh die Stadt erinnert, zusammentraf. Dasselbe creignete sich am Abend des 26. Juli. Die Einwohner durchzogen in Processionen die Strassen und errichteten Zelte, um darin den Folgen neuer Stösse zu entgehen. Der Vesuv hatte sich indess noch nicht geändert. Die Erschütterung war nicht von ihm, sondern, wie sich später ermiltelte, von fernen Landestheilen, von der Provinz ifolise, wo die verderbliche Wirkung den höchsten Grad erreicht hatte, ausgegangen.

Aber auch der Vesuv zeigte sich bald darauf in glanzvoller Thätigkeit. Plötzlich, an Abend des 12. August, stïrzte cin Feuerstrom vom Krater herunter. Sogleich waren die Freunde in einem Boote auf dem Mecre. Sie landeten bei Torre del Greco, erreichten nach Mitternacht daselbst die Lava und gelangten vor Tagesanbruch auf den Gipfel des Berges, der durch diesen Ausbruch eine nieht unbedeutende Ungestaltung erfahren hatte. Erfitlt von den Eindrïcken dieser Nacht, setzten sie ihre Beobachtungen an den folgenden Tagen beharrlich fort.

Neben den Untersuchungen in der Natur selbst beschïftigten die in Neapel befindlichen Sammlungen die fremden Forseher lebhaft. Unter ihnen hatten die des Duca della Torre von Auswurfsproducten des Vesurs und des Dr. Thompson von den vulkanischen Gesteinen ganz Italiens und der benachbarten Inseln des Mittelmecres besonderen Werth für dieselben. $\Lambda$ ber so gross die Zuvorkommenheit des ersteren, so gross war das Misstrauen des letyteren, welcher, wie Arago in seiner Biographic Gay-Lussae's erzällt, deutlich zu verstehen gal), dass er scine $\Lambda$ ugen wohl auf zwei, nicht aber auf mehr Personen haben könne.

Am 19. August kehrten die Freunde nach Rom in das gastliche Haus, von dem sie ausgegangen waren, zuriick und verblieben daselbst noch volle vier Wochen. Sodann eilten sie vereinigt dem Norden zu. 
Zwischen Florenz und Bologna wurde die geologische Structur des Apennins untersucht; in Mailand, wohin Volta sich auf einige Zeit von Como aus begeben hatte, mit diesem ïber die neuesten Entdeckungen auf dem Gebiet des Galvaniswus verhandelt, wovon Buch's Mittheilungen an Pictet $(\mathbf{I}, 524)$ Zeugniss geben. Wiahrend Humboldt und Gay-Lussac am Comersee und auf dem Gotthard magnetische Beobachtungen ausfïhrten, erklomm Buch die hohen Gipfel in der Nähc. Auf dem ganzen Wege bis zur deutschen Grenze wurden zahlreiche Höhenbestimmungen und Untersuchungen der Quellentemperatur vorgenommen. Am 4. November liessen sich bei Blumenbach in Göttingen in scherzhafter Weise drei Fremde melden, „von denen der eine am weitesten, der zweite am höchsten, der dritte am tiefsten gewesen sei". Bald darauf waren sie in Berlin.

Die Untersuchungen, welche Buch auf seiner zweiten italienischen Reise amj Vesuv angestellt hat, sind am vollständigsten in dem unter dem 6. Oetober 1805 aus Mailand an Pictet gerichteten und in der Bibliothèque britanuique abgedruckten Briefe wiedergegeben, welcher den Titel führt: "sur la dernière éruption du Vésuve et sur une nouvelle expérience galvanique." Es wird darin der Zustand des Kraters, wie ihn die Beobachter unmittelbar nach ihrer Ankunft in Neapel vorfanden, beschrieben und vermittelst eines Plans und Durchschnitts anschaulich 'gemacht; es werden die Veränderungen, welehe sich beim Lavenausbruch vom 12. August an dem Vulkan ereigneten, geselildert und der Lauf der Lava, die sich mit einer bis dahin nie beobachteten Schnelligkeit in drei Stunden bis zum Meere verbreitet hatte, durch eine Zeichnung dargestellt.

Eine etwas kiirzere Abfassung derselben Nachrichten brachte Buch im Jahre 1806, als er seine Briefe aus Neapel drucken liess, in zweiten Bande der Beobachtungen auf Reisen $(\mathrm{I}, 460)$ und fügte dort $\Lambda$ ngaben ïber die Höhen, welche die Hauptpunkte des Kraters damals erreichten, hinzu.

Zwar war der Ausbruch des 12. August nicht einer jener vollstïndigen, wie Buch sie in sciner Darstellung der Eruptionsgesetze beschrieben hat; cr war weder von dem Aufbrechen seitlicher Schlünde, noch von cinem Aschenfall und vulkanischen Regengüssen, noch von Mofetten begleitet. Er bestand nur aus einem Ueberlaufen der Lava aus dem grossen Krater, womit kcine Leerung desselben verbunden 
war; aber die daran sich knüpfenden Berichte, von einer Autorität wie der Buch'schen herrührend, werden stets wichtige Anhaltspunkte für die Geschichte des Vulkans bleiben.

Aus Buch's zweiter Reise nach Unter-Italien ist noch eine andere, zwar kurze, aber in nehrfacher Hinsicht bemerkenswerthe Arbeit hervorgegangen, seine ebenfalls im zweiten Bande der Beobachtungen auf Reisen enthaltene Abhandlung tiber den Monte Albano. Buch hatte schon vor sechs Jahren die bedeutende vulkanische Wirksamkeit, von welcher dieses Gebirge einst der Sitz gewesen war, erkannt und sah sich jetzt bei einen genaueren Studium der dortigen Ausbruchspunkte und der aus denselben hervorgegangenen Producte in dieser Ansicht bestärkt. Vortrefflich ist in seiner Schrift über das Albaner Gebirge u.A. die Beschreibung des Peperins, welcher trotz seiner Verschiedenheit vom 'Tuff der nächsten Umgegend Roms, wenn auch mit einiger Vorsicht, für ein Gestein gleicher Entstehung erklärt wird. „Wenn es in der Gebirgslehre erlaubt wäre," sagt Buch (I, 384), „durch Hypothesen dem ruhigen Gange der Beobachtungen vorgreifen zu wollen, so könnte man von solchem Vulkan die ganze Entstehung des Peperino herleiten, als wiederholte Aschenausbriiche, die auf ansehnliche Ferne verbreitet in's Meer fielen und sich hier ebneten. Mit ihnen wurden die Massen aus dem Innern geworfen, die jetzt vom Peperino uphüllt werden, die Basalte, die Kalksteine."

Bis zum Ende der hier geschilderten zweiten italienischen Reise reichen die Unternehmungen, auf welche sich der Inhalt des ersten Bandes von Buch's gesammelten Werken gründet.

Nachdem wir gesehen haben, wie Buch den Boden Schritt für Schritt erkämpfen musste, auf den seine eigenen Ideen sich erst entwickeln konnten, nachdem wir überall auf diesem Boden bereits die Keime zu seinen nachmaligen Anschauungen haben emporspriessen sehen, wird im Verfolg der gegenwärtigen Lebensskizze zu zeigen sein, auf welche Weise sich diese Keime zu den grossen Schöpfungen entfaltet haben, die ihn die Wissenschaft verdankt. 